\title{
The antagonism between MCT-1 and p53 affects the tumorigenic outcomes
}

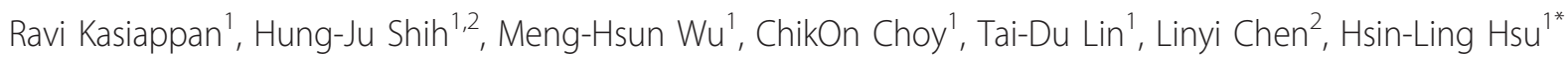

\begin{abstract}
Background: MCT-1 oncoprotein accelerates p53 protein degradation via a proteosome pathway. Synergistic promotion of the xenograft tumorigenicity has been demonstrated in circumstance of p53 loss alongside MCT-1 overexpression. However, the molecular regulation between MCT-1 and p53 in tumor development remains ambiguous. We speculate that MCT-1 may counteract p53 through the diverse mechanisms that determine the tumorigenic outcomes.
\end{abstract}

Results: MCT-1 has now identified as a novel target gene of p53 transcriptional regulation. MCT-1 promoter region contains the response elements reactive with wild-type p53 but not mutant p53. Functional p53 suppresses MCT-1 promoter activity and MCT-1 mRNA stability. In a negative feedback regulation, constitutively expressed MCT-1 decreases p53 promoter function and p53 mRNA stability. The apoptotic events are also significantly prevented by oncogenic MCT-1 in a p53-dependent or a p53-independent fashion, according to the genotoxic mechanism. Moreover, oncogenic MCT-1 promotes the tumorigenicity in mice xenografts of p53-null and p53-positive lung cancer cells. In support of the tumor growth are irrepressible by p53 reactivation in vivo, the inhibitors of p53 (MDM2, Pirh2, and Cop1) are constantly stimulated by MCT-1 oncoprotein.

Conclusions: The oppositions between MCT-1 and p53 are firstly confirmed at multistage processes that include transcription control, mRNA metabolism, and protein expression. MCT-1 oncogenicity can overcome p53 function that persistently advances the tumor development.

\section{Background}

Mutations or loss of the tumor suppressor p53 gene have been documented in more than $50 \%$ of human cancers [1-3]. Functional p53 is involved in the regulation of genomic integrity, growth arrest, DNA repair, programmed cell death, and cell differentiation [3-5]. As a transcription factor, p53 binds specifically to the consensus DNA sequence consisting of two copies of the 10-bp motif 5'-RRRC(A/T)(T/A)GYYY-3', in which R is a purine and $\mathrm{Y}$ is a pyrimidine, separating by a 1-13 base pair (bp) junction [6-8]. These specific sequences are recognized in the p53 regulatory genes, such as Pirh2 [9], Cop1 [10], Waf-1/p21 [11], MDM2 [12], Bax [13], and PCNA [14]. Numerous p53 downstream targets are implicated in tumor suppression. But Pirh2, MDM2, and Cop1 are ubiquitin ligases implicated in

\footnotetext{
* Correspondence: hsinling88@nhri.org.tw

'Division of Molecular and Genomic Medicine, National Health Research

Institutes, 35 Keyan Road, Zhunan, Miaoli County 350, Taiwan

Full list of author information is available at the end of the article
}

tumor development that mediate p53 degradation in a proteosome manner $[9,10,15]$. The genome-wide ChIP studies have also indentified the p53-regulatory genes BCL2A1, PTK2 and VIM that associate with tumor formation [16,17].

The activity of p53 exerts paradoxically anti-apoptotic and pro-survival effects, which are essential for the development of an organism and may turn p53 into a tumor promoter. As a comprehensive guardian of genome integrity, p53 confers the survival-promoting advantages of cancer cells [18]. More substantial evidence have emerged that $\mathrm{p} 53$ protects cells from the genotoxin-induced apoptosis [19-21]. Though p53 induces Bax activation and apoptosis, relocating the p53 protein to mitochondria does not trigger tumor cell death, conversely grants apoptotic resistance to ionizing radiation [22]. Moreover, p53 reduces the oxidationinduced DNA damage and apoptosis [23-25]. Overall, p53 has its dark side that enhances the cell surviving mechanism and potentially inititates tumorigenicity. 
Exploration of p53 antagonists or p53 downstream targets which are implicated in tumorigenesis, is thus a very important task.

MCT-1 (multiple copies in T cell malignancy 1) oncogene is highly expressed in the human lymphomas $[26,27]$. Overexpression of MCT-1 promotes cell survival, proliferation, checkpoint bypass, and anchorageindependent growth $[26,28,29]$. Constitutively expressed MCT-1 transforms normal breast epithelial MCF-10A cells [30], and increases the tumorigenicity of breast cancer MCF-7 cell xenografted mice, possibly through promoting angiogenesis and anti-apoptosis [31]. MCT-1 protein interacts with the ribosome and associates with the cap complex by the putative RNA-binding motif, PUA domain [32,33]. Ectopic MCT-1 also promotes translational initiation of many cancer-related mRNAs, including BCL2L2, Cyclin D1, TFDP1, MRE11A and E2F1 [34]. Furthermore, ectopically expressed MCT-1 decreases p53 mRNA levels and p53 protein stability in vitro $[35,36]$.

The regulations in opposition between p53 and MCT1 have now been verified in vitro and in vivo. The wildtype p53 targeting the $M C T-1$ gene promoter could affect the presentation of MCT-1 mRAN and protein. Reciprocally, MCT-1 depresses p53 gene promoter, mRNA stability, and protein function. Moreover, the reactivation of p53 cannot restrain the MCT-1 tumorigenic impacts on H1299 (p53 null) lung cancer cells xenografted mice and the stimulation of p53 repressors (MDM2, Pirh2, and Cop1). As well, the oncogenic MCT-1 persistently promotes the xenograft tumorigenicity of A549 (p53 wild-type) lung cancer cells. These data reveal that MCT-1 advances cellular malignancy and tumorigenic potency independent of p53 status.

\section{Results}

\section{MCT-1 gene and protein are downregulated by $\mathrm{p} 53$}

To investigate whether p53 affected intrinsic MCT-1 gene activation, the non-small cell lung cancer H1299 (p53 null) cells were transfected with pCDNA vector alone or pCDNA-p53 to rebuild p53 function (control + p53, MCT-1 + p53). For examining the MCT-1 promoter function, a $1.3 \mathrm{~kb} M C T-1$ gene promoter segment $(-1301$ to +37$)$ was engineered into a pGL3-luciferase basic vector. The pGL3-MCT-1 promoter construct was then introduced into the control H1299 cells (control) that expressed with the vector alone (pCDNA), the wild-type p53 (pCDNA-p53), or the mutant p53 (pCDNA-p53mt135) (Figure 1A). Cells presenting wildtype p53, the pGL3-MCT-1 luciferase activity was depressed markedly to $60 \%$ of promoter activity of cells without p53 (vector) ( $\mathrm{p}<0.0001)$. Conversely, the pGL3-MCT-1 promoter activity was unchanged by the mutant p53, revealing that only the functional p53 particularly deactivated the $M C T-1$ gene promoter. Similar data was also presented in context of pLXSNMCT-1 expressed H1299 (MCT-1) that only wild-type p53 affected MCT-1 promoter activity. To exclude the possibility that p53 non-specifically obstructed the promoter function, the 5'LTR promoter segment of pLXSN was constructed into a pGL3-Luciferase basic vector. Obviously, the p53 showed no effect on the reporter activity of pGL3-5'LTR (Additional File 1A).

To further analyze the half-life $\left(t_{1 / 2}\right)$ of MCT-1 mRNA in $\mathrm{H} 1299$ cell present or absent of p53, Actinomycin D was used for inhibition of de novo gene transcription (Figure 1B). Cellular RNA samples were then harvested at the indicated intervals to measure MCT-1 mRNA quantities by qRT-PCR study. Results indicated that the intrinsic MCT-1 mRNA decayed faster in cells having $\mathrm{p} 53\left(\mathrm{t}_{1 / 2}=3.1 \mathrm{~h}\right)($ control $+\mathrm{p} 53$, filled square $)$ than those lacking p53 ( $\left.\mathrm{t}_{1 / 2}=4.01 \mathrm{~h}\right)$ (control, open square). As well, the $M C T-1$ gene expression was examined after cells transfecting with pLXSN vector alone (control) or pLXSN-MCT-1 (MCT-1). Similar to intrinsic MCT-1 mRNA turnover, p53 renovation also negatively regulated the steady-state of ectopic MCT-1 mRNA that decomposed rapidly $\left(\mathrm{t}_{1 / 2}=3.5 \mathrm{~h}\right)(\mathrm{MCT}-1+\mathrm{p} 53$, filled triangle) comparing with $\mathrm{p} 53$ absent condition $\left(\mathrm{t}_{1 / 2}=\right.$ $4.5 \mathrm{~h}$ ) (MCT-1, open triangle). The effect of p53-dependent destabilization of MCT-1 mRNA stability was inhibited as MCT-1 mRNA was much stable in the MCT $-1+$ p53 cells $\left(t_{1 / 2}=3.5\right)$ than the control + p53 cells $\left(t_{1 / 2}=3.1\right)$, possibly ectopic MCT-1 performing a negative impact on p53 role.

By quantifying the overall MCT-1 mRNA levels with qRT-PCR analysis (Figure 1C), MCT-1 mRNA levels in the p53 gene-restored H1299 cells (control + p53) were found to be decreased to $71 \%$ of that of sample without the p53 expression (control + vector). Consistent with decrease in cellular MCT-1 mRNA levels by $\mathrm{p} 53$, the levels of exogenic MCT-1 mRNA (MCT-1 + p53) (6.78) also dramatically reduced to $54 \%$ of that of the vector controls (MCT-1 + vector) (12.54) as well. These data demonstrate that the $\mathrm{p} 53$ reactivation can effectively repress $M C T-1$ gene presentation.

Further analysis was examined whether p53 reduction conversely improved MCT-1 expression in normal breast epithelial MCF-10A cells with wild-type p53 and regular genetic background (Figure 1D). MCT-1 protein levels were detected by the specific Ab against a synthetic peptide (a.a. 72-88) of MCT-1 polypeptide. Following etoposide (ETO) genotoxin treatment for $4 \mathrm{~h}$, cellular p53 was accumulated and functionally activated. MCT-1 amount was found to be a 2-fold increase after p53 silencing (p53 shRNA) relative to the non-silence control (MOCK) (lanes 1 vs. 3). Moreover, ectopic MCT-1 protein (V5-tag) was recognized by the V5-epitope Ab that 


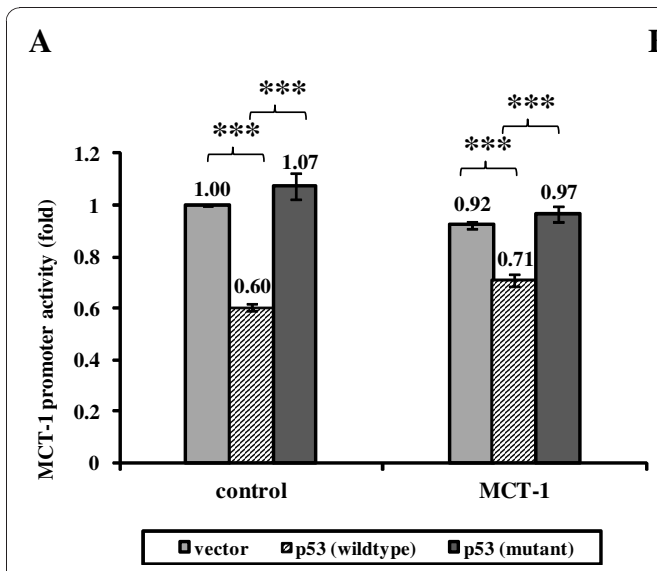

C

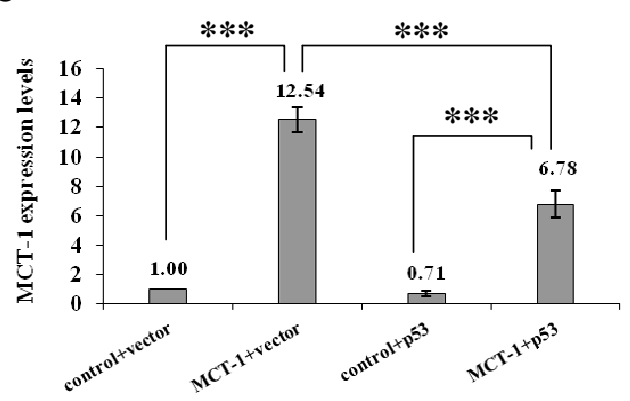

B

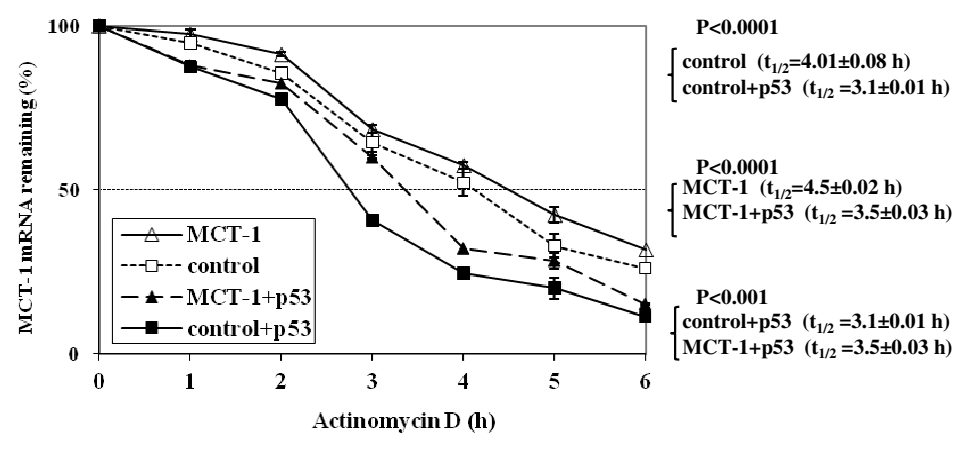

$\mathbf{E}$
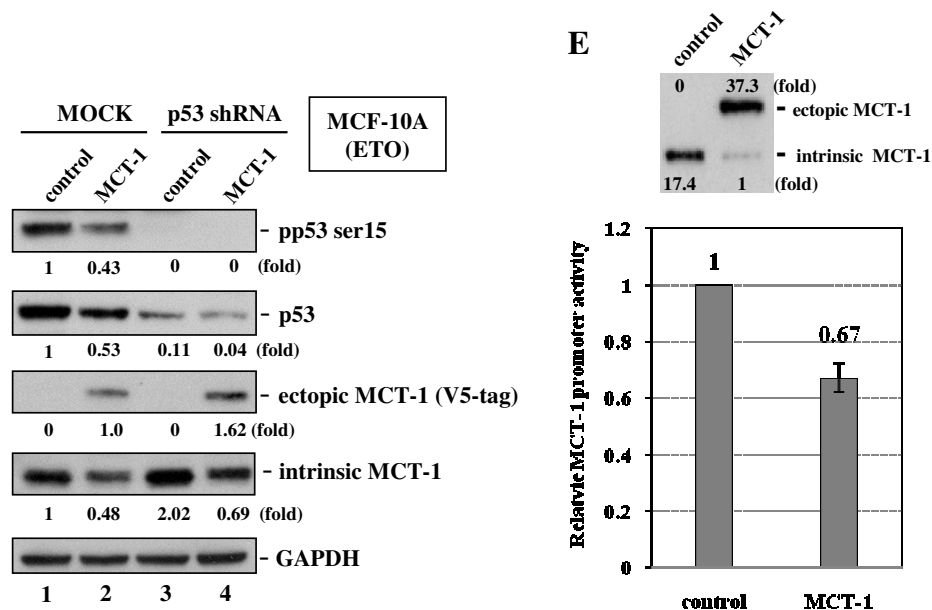

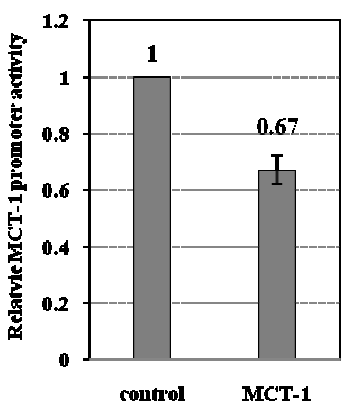

Figure 1 MCT-1 gene and protein expressions are decreased by p53. The pGL3-MCT-1 promoter construct was transiently transfected into H1299 (p53 null) cells. (A) Reduced luciferase activity of the pGL3-MCT-1 reporter was identified when H1299 cells (control) expressed the wildtype p53 but not the mutant p53. Similar effects were recognized in context of MCT-1 overexpression (MCT-1) (B) The half-life $\left(t_{1 / 2}\right)$ of MCT-1 mRNA was analyzed by qRT-PCR after actinomycin D $(5 \mu \mathrm{g} / \mathrm{ml})$ treatment for the indicated time. Quantitative data was acquired as normalized with $18 \mathrm{~S}$ rRNA levels. Cellular MCT-1 mRNA turnover was greater induced by p53 expression (control + p53) than p53 null condition (control). The exogenic MCT-1 mRNA decayed quickly in p53 renovation (MCT-1 + p53) versus (vs.) without p53 expression (MCT-1). (C) As determined with qRT-PCR analysis, the p53 knock-in H1299 moderately depressed intrinsic MCT-1 mRNA levels (control vs. control + p53). As well, the exogenic MCT-1 mRNA levels were significantly depressed by p53 (MCT-1 vs. MCT-1 + p53). (D) MCF-10A cells were under ETO genotoxic stress for $4 \mathrm{~h}$. The ectopic (V5-tag) and intrinsic MCT-1 protein in MCF-10A (p53-proficient) cells were reversely elevated because p53 gene silence (p53 shRNA) relative to MOCK experiment. (E) Ectopic expression of MCT-1 reduced PGL3-MCT-1 promoter activity together with decrease in intrinsic MCT-1 protein. The overall cellular MCT-1 protein amounts (intrinsic plus ectopic) were more than a 2.2-fold elevation after MCT-1 induction. Statistics were analyzed with Student's t test. ${ }^{* *} p<0.0001$.

showed a 1.62-fold elevation after p53 knockdown comparative to the non-silence group (lanes 2 vs. 4). These validate that p53 presence actually counteracts MCT-1 protein production.

The unexpected data indicated that intrinsic MCT-1 protein was dramatically inhibited after ectopic MCT-1 expression (Figure 1E). As well, the autoregulation of $M C T-1$ gene presentation was identified as the pGL3MCT-1 promoter activity was diminished by ectopic MCT-1 to $67 \%$ of that of control group. Even so, the entire MCT-1 protein amounts (ectopic plus intrinsic) still promoted to a 2.2-fold induction as compared with control group. These data establish for the first time that MCT-1 controls itself, via a feedback loop involving the promoter downregualtion.

\section{Interaction of $\mathrm{p} 53$ with the MCT-1 promoter region}

MCT-1 promoter region was searching for the consensus p53-binding element, 5'-RRRC(A/T)(T/A)GYYY-3', using the NTI vector program. Six potential p53-binding sites were identified at the MCT-1 promoter region that located between nucleotides (nt.) -1301 and -801 (Figure 2A). ChIP analysis was studied whether the MCT-1 promoter DNA associated with the activated $\mathrm{p} 53$ protein under ETO genotoxic stress in MCF-10A cells (Figure 2B). Immune complex of p53 antibody (p53 Ab-IP) were 


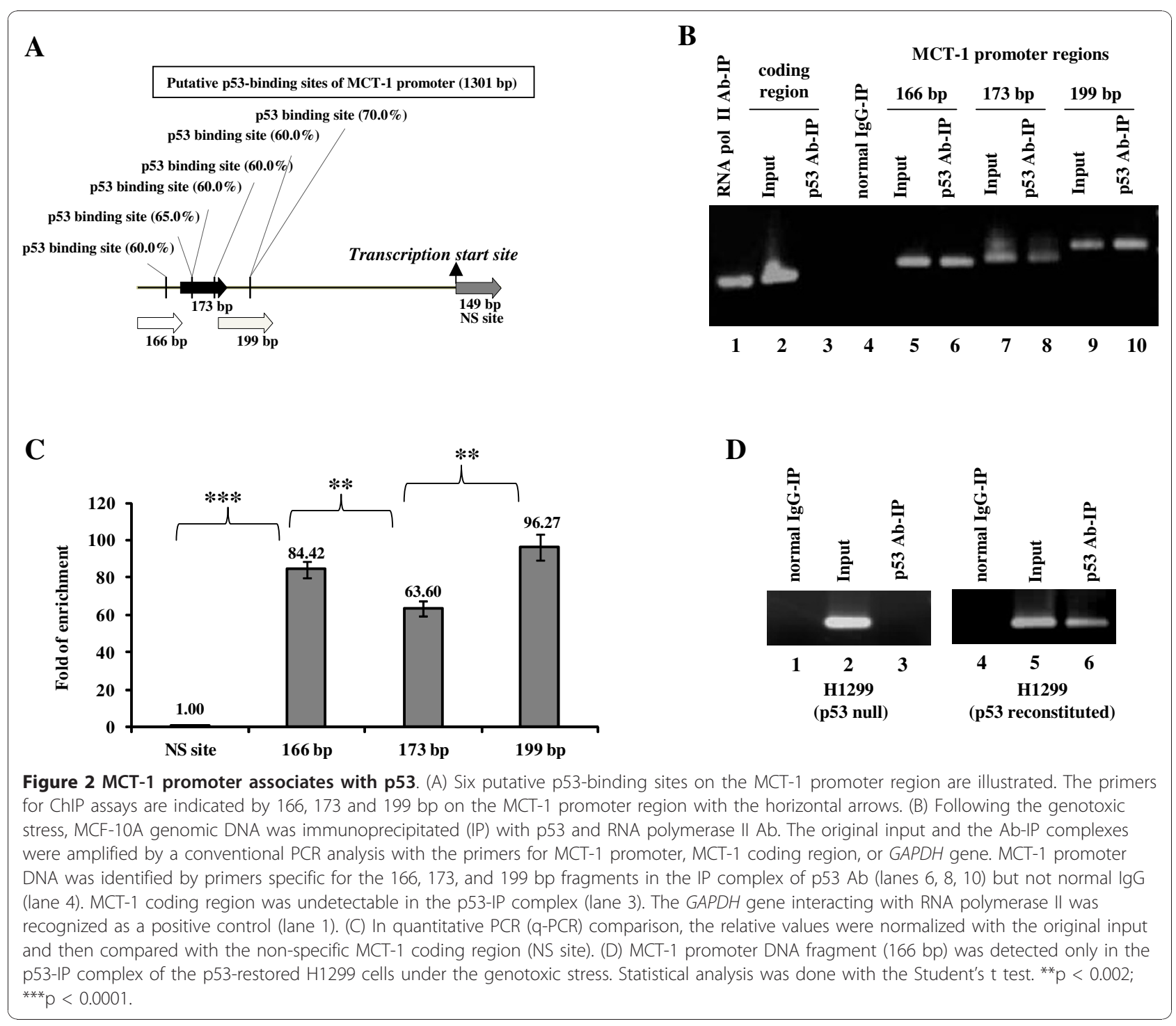

PCR-amplified with the primers (Additional File 2) for the MCT-1 promoter region that correspondingly produced DNA fragment sizes of 166, 173 and 199 base pair (bp). Conversely, the nonspecific (NS) site located at the MCT1 coding region (nt. 1 149) was undetectable in the p53 Ab-IP complex. The RNA polymerase II specifically recognized $G A P D H$ gene as a positive control, but no DNA associated with normal IgG. Using a qPCR analysis to quantify ChIP results, the 166 and 199 bp locations exhibited higher associations with p53 than that of the $173 \mathrm{bp}$ region $(\mathrm{p}<0.002)$ (Figure $2 \mathrm{C}$ ), indicating their differential connections with $\mathrm{p} 53$ protein. Furthermore, the parental (p53 null) or the p53 gene restored H1299 cells (p53-reconstituted) were conducted with ChIP studies (Figure 2D). The MCT-1 promoter DNA was only detectable in the p53-IP complex of the p53-reconstituted sample but not in the parental group. Though no p53 repressor element (p53TRE) is noticed in the MCT-1 promoter region, the relation of $\mathrm{p} 53$ protein with $\mathrm{MCT}-1$ promoter may obstruct $M C T-1$ gene transcription.

Electrophoretic-mobility shift assay (EMSA) was investigated whether p53 protein closely interacted with the MCT-1 promoter sites. Biotin-labeled probes (166, 173, and $199 \mathrm{bp}$ ), covering the promoter region from -1301 to -801 (Figure 2A), were prepared and incubated with nuclear extracts (NE) from MCF-10A cells after etoposide (ETO) treatment that stimulated and stabilized p53 protein. The biotinylated 166 bp probe formed a complex with the nuclear protein as indicated by a mobility shift (Figure 3A, lane 3). This specific DNA-protein complex was dramatically competed by a 100-fold excess of the p53 consensus oligonucleotides (lane 4) but not the mutant p53-responsive element (lane 5). Furthermore, p53 existence in the complex was proved 


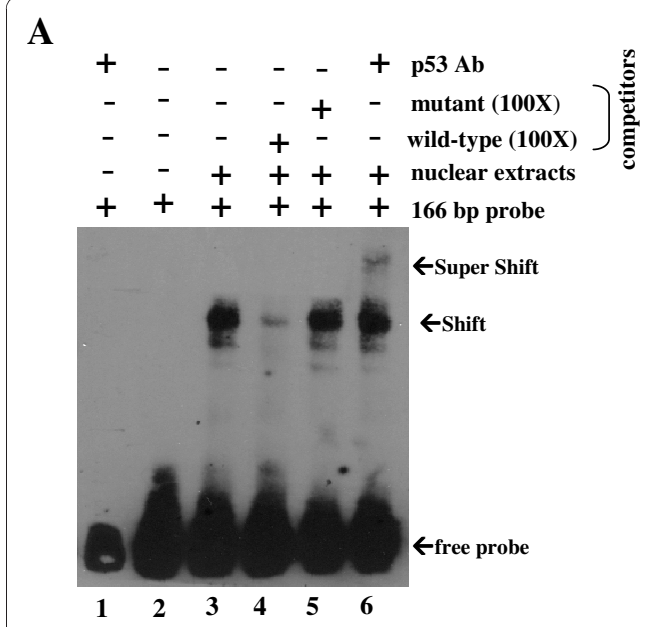

B
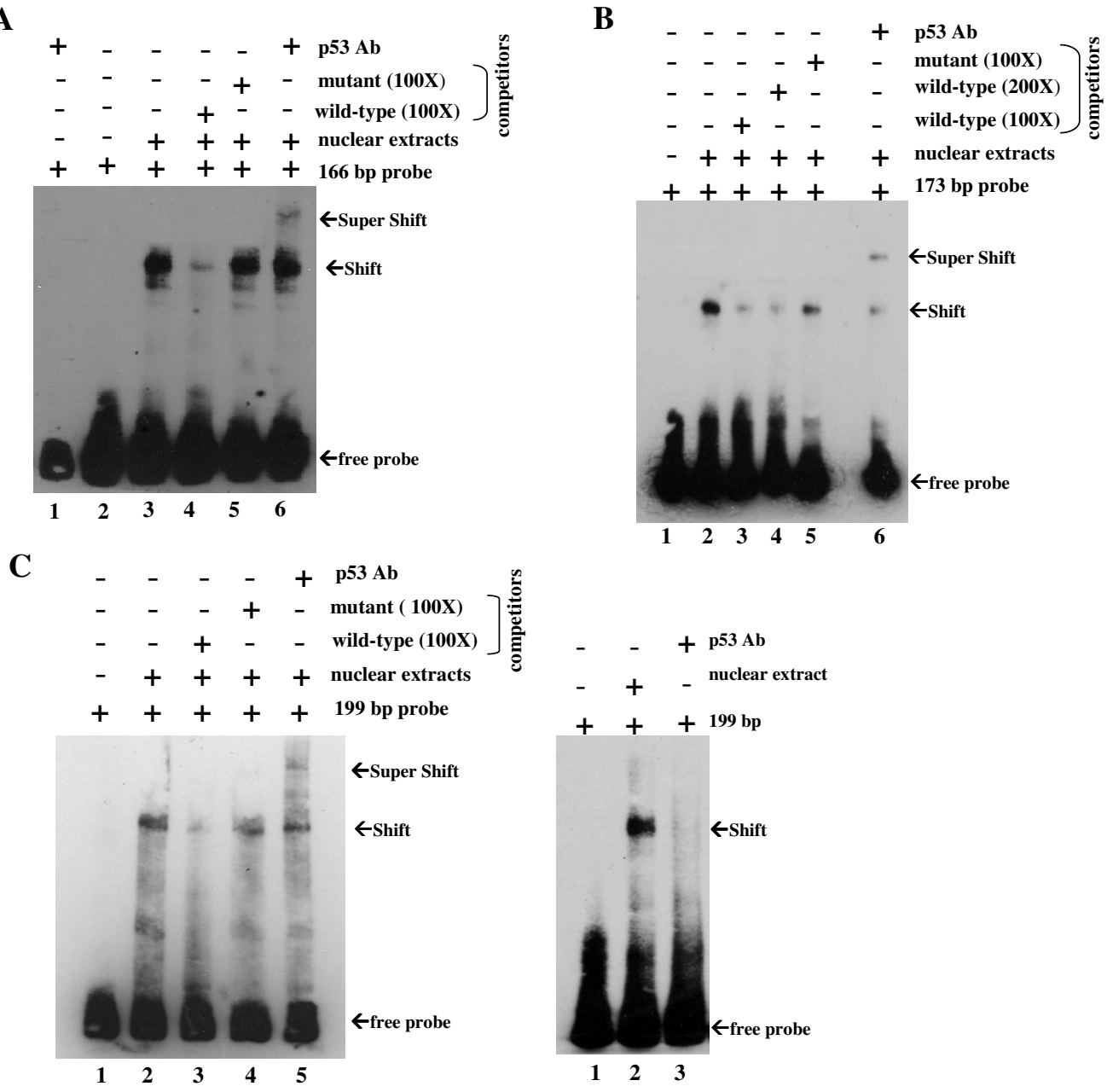

Figure 3 Binding of p53 to the MCT-1 promoter region. EMSA was conducted by incubating the MCT-1 promoter probes with nuclear extracts of MCF-10A cells after the genotoxin (ETO) treatment. (A) The biotin-labeled 166 bp probe formed a complex with the nuclear protein (lane 3). This complex was partially depleted by the wild-type (lane 4) but not by the mutant (lane 5) p53-responsive elements in a 100X excess concentration. The presence of p53 in complex was confirmed by inducing a super-shift complex with p53 Ab (lane 6). No specific interaction between the probe and p53 Ab was recognized (lane 1). (B) The biotin-labeled 173 bp probe formed a DNA-protein complex with the nuclear protein (lane 2). This complex was partially reduced by the wild-type competitor at concentrations of 100X excess (lane 3) and 200X excess (lane 4), but it was not depleted by the mutant competitor at a concentration of 100X excess (lane 5). The presence of p53 in complex was confirmed by the p53 Ab inducing a super-mobility shift (lane 6). No specific complex formed between the probe and p53 Ab (right panel). (C) The biotin-labeled 199 bp probe interacted with the nuclear protein (lane 2). This DNA-protein complex was specifically interrupted by wild-type (lane 3) but not the mutant p53-responsive competitor at a concentration of 100X excess (lane 4). A super-shift band was identified as p53 Ab reacted with the DNA-protein complex (lane 5). Again, no particular complex produced among the probe and p53 Ab (right panel).

by generating a super-shifted band after incubation with the p53-specific antibody (lane 6). But, no obvious complex formed between the p53 Ab and the DNA probe alone (lane 1).

On the other hand, the biotinylated 173 bp probe revealed a specific interaction with the nuclear protein (Figure 3B, lane 2), which was greatly attenuated by adding a 100- or 200-fold excess of p53 consensus oligonucleotide (lanes 3 and 4). A super-shifted band was evidently induced by the p53 $\mathrm{Ab}$, confirming the presence of $\mathrm{p} 53$ protein in the complex (lane 6). On the contrary, the
DNA-protein complex was unable to be depleted by the mutant p53-responsive element (lane 5). As well, no detectable complex was produced between the p53 Ab and the DNA probe alone (Figure 3B, right panel).

Another DNA-protein complex was recognized while the nuclear extracts reacting with the biotinylated $199 \mathrm{bp}$ probe (Figure 3C, lane 2). This complex was also significantly repressed by a 100-fold excess of the wild-type p53 consensus oligonucleotide (lane 3), but it was insignificantly contended by the mutant p53-responsive element (lane 4). A super-shifted mobility caused by the p53 Ab 
clarified p53 being in the DNA-protein complex (lane 5). Moreover, no specific DNA-protein complex was generated between p53 Ab and the DNA probe (Figure 3C, right panel). These data have evidently proved that $\mathrm{p} 53$ protein interacts with the promoter of $M C T-1$ gene.

\section{MCT-1 inhibits p53 promoter activation and protein expression}

ChIP assay was again evaluated if the MCT-1 protein reciprocally associated with $p 53$ gene promoter (Figure 4A). The $\mathrm{p} 53$ promoter-specific primers ranging from -420 to -84 were identified whether the $p 53$ promoter DNA contained in the IP complex of MCT-1 Ab. In a PCR amplification analysis, approximately $8.9 \%$ of $p 53$ promoter DNA was discovered in MCT-1 immune complex (IP). Control experiments had identified that GAPDH gene specifically associated with RNA polymerase II, but no genomic DNA was coupled with a normal IgG. Different from p53 specific binding with the MCT-1 promoter DNA (Figure 3), no interaction was detected between the p53 promoter DNA and MCT-1 protein in the EMSA study (data not shown). It is possible that MCT-1 could cooperate with other undisclosed molecule(s) that closely interact with the $p 53$ gene promoter.
A

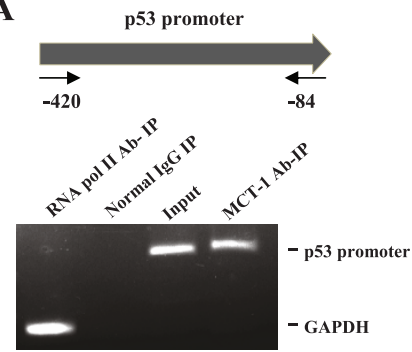

B

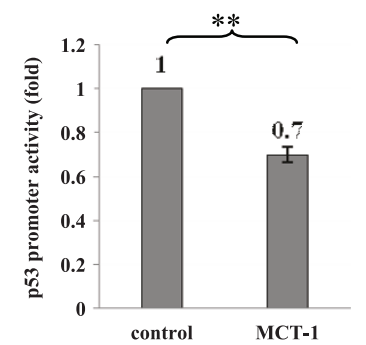

C

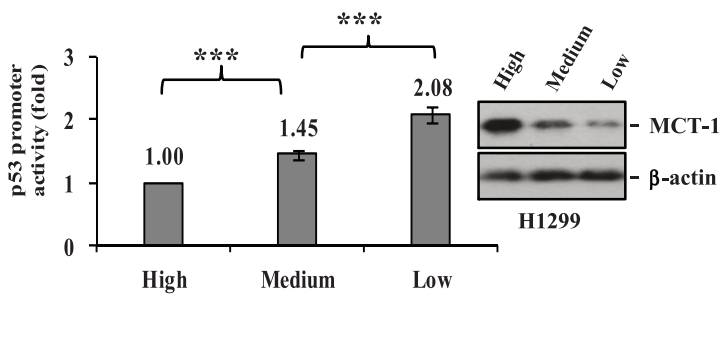

D

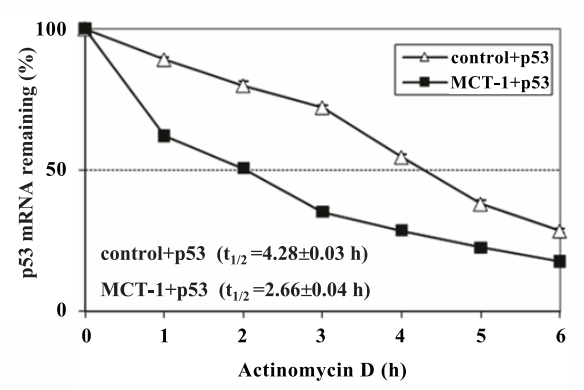

$\mathbf{E}$

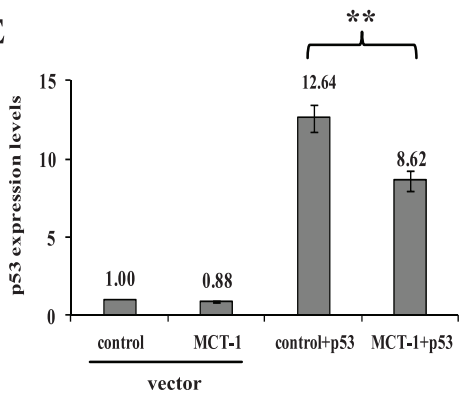

F

H1299 (ETO, 4 h)

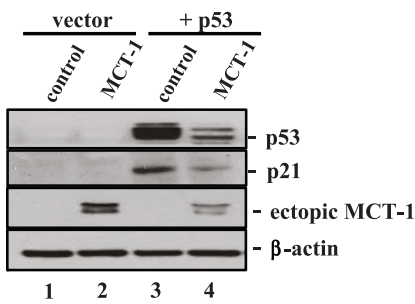

G

MCF-10A (ET0)

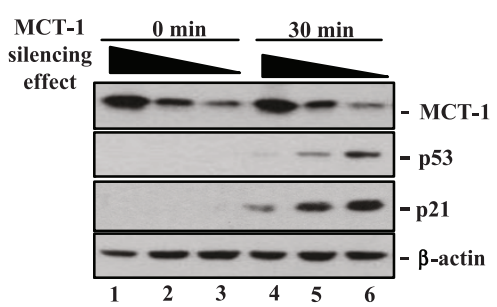

н

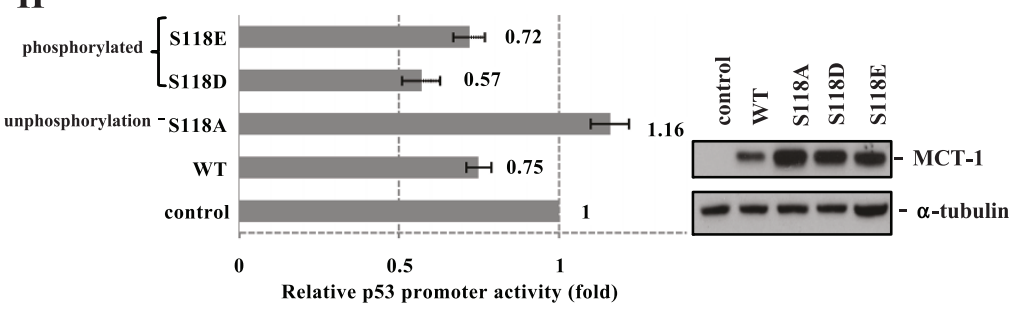

Figure 4 MCT-1 decreases p53 promoter function and protein expression. (A) The primers of p53 promoter region (-420 to -84$)$ were hybridized with the ChIP complex. The p53 promoter DNA specifically contained in the IP complex of MCT-1 Ab but not normal lgG. (B) Luciferase activity of the pGL3-p53 promoter was depressed by ectopic MCT-1 (MCT-1) compared with control H1299 (control). (C) The pGL3-p53 promoter was conversely activated while MCT-1 silencing in H1299 context. (D) The half-life of exogenic p53 mRNA was decreased in ectopic MCT-1 group (MCT-1 + p53) relative to the corresponding control (control + p53) $(\mathrm{P}<0.0001)$. (E) The overall p53 mRNA productions in the p53-restored H1299 cells were declined evidently in ectopic MCT-1 background (MCT-1 + p53). (F) Upon etoposide (ETO) exposure for 4 h, ectopic MCT-1 reduced the p53 functional activation of p21 (lanes 3 vs. 4). (G) The shRNA interference of intrinsic MCT-1 in MCF-10A cells conversely stimulated p53 and p21 proteins upon ETO treatment for $30 \mathrm{~min}$. (H) The effects of wild-type MCT-1 (WT) and MCT-1 mutants that were directly mutated on Serine 118 residue (S118) to Alanine (S118A), Aspartic acid (S118D), and Glutamic acid (S118E) were studied. The dephosphorylation mutant (S118A) significantly improved the pGL3-p53 promoter function, but pGL3-p53 promoter was still repressed by cells expressing the phosphorylation-mimetic MCT-1 (S118D and S118E) and wild-type MCT-1. Statistical data was assessed with the Student's t test. ${ }^{* *} p<0.002 ;{ }^{* * *} p<0.0001$. 
The proximal p53 promoter region $(-188$ to +12$)$ contains a full promoter activity in the response to DNA damage $[37,38]$. To study whether ectopic MCT-1 antagonized p53 promoter activity, the p53 promoter DNA $(-188$ to +23$)$ segment was cloned into the pGL3Luc basic vector and then transfected into H1299 cells. The luciferase activity of pGL3-p53 promoter in ectopic MCT-1 group was decreased approximately to $70 \%$ of the respective control group (control) (Figure 4B), indicating that MCT-1 functionally inactivated p53 promoter. The activity of CMV promoter of pCDNA3.1 that was cloned into the pGL3-Luc basic vector was not affected by the MCT-1, excluding the possibility that ectopic MCT-1 non-specifically affected the promoter function (Additional File 1B).

To analyze if MCT-1 status directly involved in $p 53$ gene deactivation, $M C T-1$ gene was knocked down by MCTS1 shRNA in H1299 cells that reduced cellular MCT-1 protein to different degrees (high, medium, low) (Figure 4C). By contrast with suppression of MCT-1 protein levels, the pGL3-p53 promoter activity was progressively improved. As compared with low p53 promoter activity in high MCT-1 context, the reporter activity was conversely elevated up to a 2 -fold induction while MCT-1 declined significantly. These verify that MCT-1 plays a critical role in regulation of $p 53$ gene promoter.

We speculated that MCT-1 also repressed the $p 53$ gene reactivation in $\mathrm{H} 1299$ cells, the metabolism of exogenic p53 mRNA was analyzed after de novo gene transcription being inhibited by actinomycin D (Figure 4D). The remaining of p53 mRNA quantity was assessed with qRT-PCR analysis at each time point. Unlike exogenic p53 mRNA decayed quickly under MCT-1 oncogenic influence $\left(\mathrm{t}_{1 / 2}=2.66 \mathrm{~h}\right)(\mathrm{MCT}-1+\mathrm{p} 53$, close square), the p53 mRNA was relatively stable in control group $\left(\mathrm{t}_{1 / 2}=4.28 \mathrm{~h}\right)$ (control $+\mathrm{p} 53$, open triangle). Further assessment with qRT-PCR study, we found that the total p53 mRNA quantities in ectopic MCT-1 cells (MCT-1 + p53) were dropped to $68 \%$ of that of controls (control + p53) (Figure 4E). Taken together, these results firstly illustrate that MCT-1 inhibits the overall p53 mRNA expression by decreasing p53 promoter function and p53 mRNA stability.

Consistent with the $p 53$ gene deactivation and p53 mRNA reduction (Figure 4B-4E), the ectopic p53 that functionally stimulated the $\mathrm{p} 21$ protein expression upon etoposide (ETO) exposure for $4 \mathrm{~h}$ was greatly suppressed by MCT-1 (MCT-1 + p53) relative to the control H1299 (control + p53) (Figure 4F, lanes 3 vs. 4). Confirmative data also revealed that MCTS1 shRNA interference reversely elevated p53 and p21 proteins in MCF-10A cells exposure to ETO (30 min) (Figure 4G). Thus, MCT-1 overexpression effectively counteracts the p53-p21 signaling function that is reversible after MCT-1 knockdown.

MCT-1 overexpression activating the extracellular signal-regulated kinase activity (ERK) is link with p53 degradation (35). To test the functional domain responsible for p53 promoter deactivation (Figure 4H), the Serine 118 (S118) residue of the potential MAPK kinase phosphorylation site on MCT-1 protein was specifically mutated to Alanine (S118A). As well, MCT-1 (S118) residue was modified to Glutamic acid (S118E) and to Aspartic acid (S118D) that were mimetic to the phosphor-S118 MCT-1. Surprisingly, only the S118A mutant restored the $\mathrm{p} 53$ promoter activity significantly, but the phosphorylation-mimetic MCT-1 (S118E and S118D) still decreased p53 promoter to an extent comparable to wild-type (WT). These suggest that the serine 118 residue on MCT-1 is essential and sufficient for inhibition of $\mathrm{p} 53$ promoter function.

\section{MCT-1 oncogenic effects in p53-dependent and p53-independent manners}

To evaluate the cooperative impact of p53 loss and MCT-1 oncogenicity on cell survival (Figure 5A), MCF$10 \mathrm{~A}$ cells induced with (MCT-1) or without MCT-1 (control) were subsequently knocked down cellular p53 protein (control-p53 and MCT-1-p53). Following exposure to hydrogen peroxide $\left(\mathrm{H}_{2} \mathrm{O}_{2}, 5 \mu \mathrm{M}\right)$ for $24 \mathrm{~h}$, cell death was analyzed with FITC-Annexin V flow cytometry. Ectopic MCT-1 cells showed a lower apoptotic outcome $(20 \%)$ than that was detected in p53-proficient controls (44\%). After p53 loss, cell death induced by the oxidative damage was promoted equally in control-p53 (67\%) and MCT-1-p53 (64\%) situations. These indicate that MCT-1 protects cells from the oxidative stress relying on p53 function.

On the other hand, a radiomimetic agent, Bleomycin (BLM) was treated MCF-10A cells (Figure 5B). Death events were not significantly induced in p53 proficient background (control and MCT-1). But, cells deficient with p53 (control-p53 and MCT-1-p53) increased incidence of apoptosis upon BLM exposure. Even so, the apoptotic populations were still less detected in MCT-1p53 group (14.9\%) than control-p53 set (26.0\%), revealing that MCT-1 protected cells from BLM genotoxicity independent of p53 function.

Cell migratory ability was moreover investigated by Fluorimetric cell migration assay (Figure 5C). While culturing in the complete media, cell mobility was notably enhanced in p53 knockdown (control-p53 and MCT-1p53) but unaffected by inducing MCT-1. Cell motility mainly enhanced by loss of p53 function may be related with Rho signaling pathway that controls actin cytoskeleton organization as literatures demonstrate [39]. 


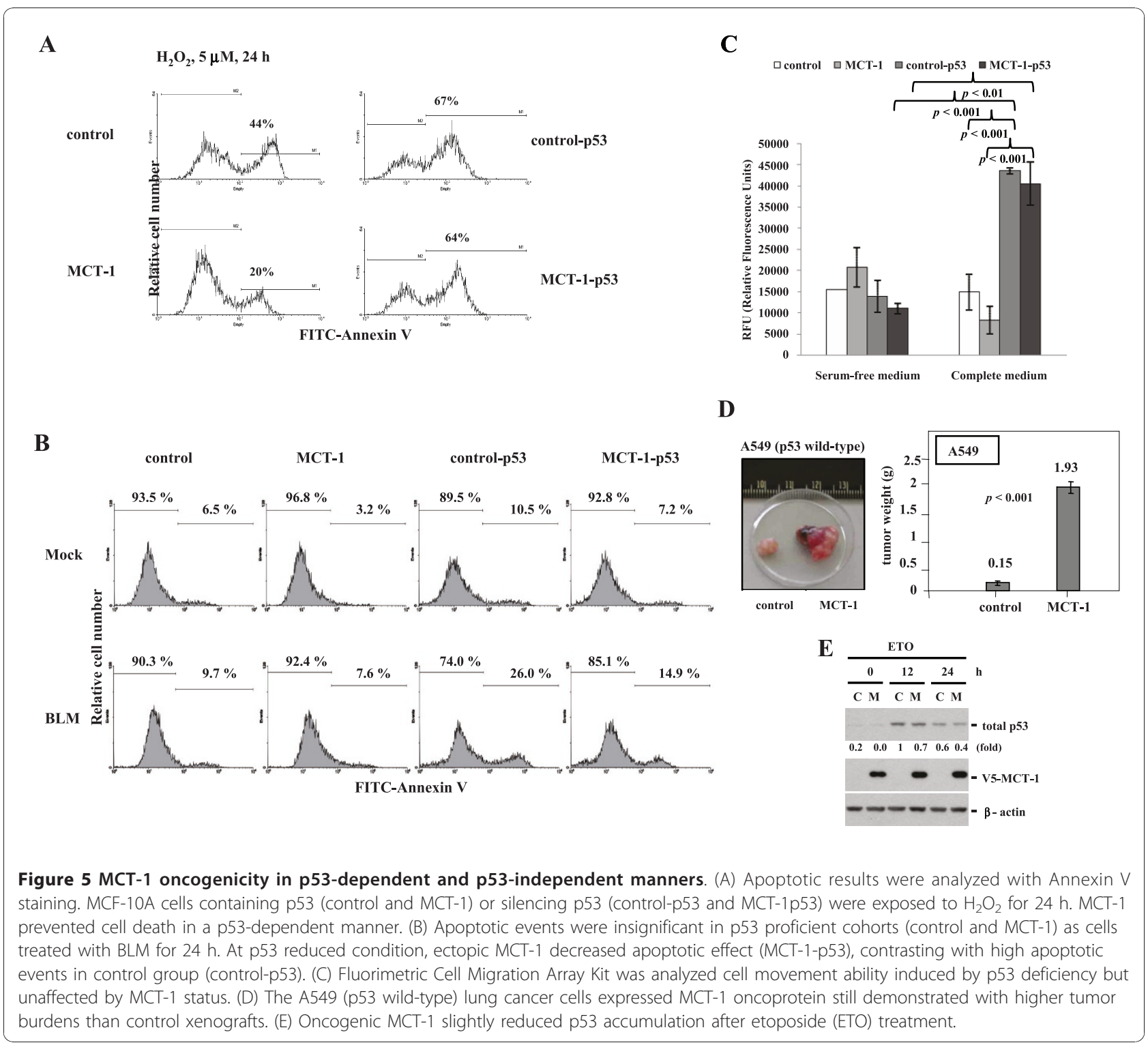

To confirm MCT-1 tumorigenic potency in a p53 wild-type background, A549 lung adenocarcinoma cells ectopically expressed MCT-1 oncogene also slightly suppressed p53 accumulation in the response to ETO genotoxin (Figure 5E). Following A549 cells subcutaneously injected into the nude mice, the tumorigenic results had evidently proved that MCT-1 oncogene strongly promoted the tumor development to a 12.8-fold increase in comparison with the control A549 xenografts (Figure 5D). Therefore, MCT-1 oncogenicity could go beyond p53 function in the tumorigenic development.

\section{MCT-1 promotes tumorigenicity independent of p53}

\section{status}

It was unidentified whether wild-type $p 53$ gene reconstitution in the p53 null background relieved MCT-1 oncogenicity. The impact of p53 restoration on chromosome copy number was surveyed by a cytogenetic study [36]. The intrinsic gene mutations (chromosome amplification) in H1299 background (copy number = 101) did not obviously improve after $p 53$ gene reconstitution (copy number $=97$ ) or change as MCT-1 overexpressed (copy number $=97$ ). These suggest that $\mathrm{p} 53$ reactivation probably cannot alter MCT-1 tumorigenic outcomes.

To explore whether MCT-1 oncogene continually antagonizes p53 function in vivo, different types of $\mathrm{H} 1299$ cells (control, MCT-1, control + p53, MCT-1 + p53) were subcutaneously inoculated into athymic BALB/c mice. The xenograft tumor burdens were enhanced dramatically in the mice engrafted with MCT-1 and MCT-1 + p53 expressed cells as compared with their corresponding control and control + p53 cells $(\mathrm{p}<0.0001)$ (Figure 6A). Moreover, the 


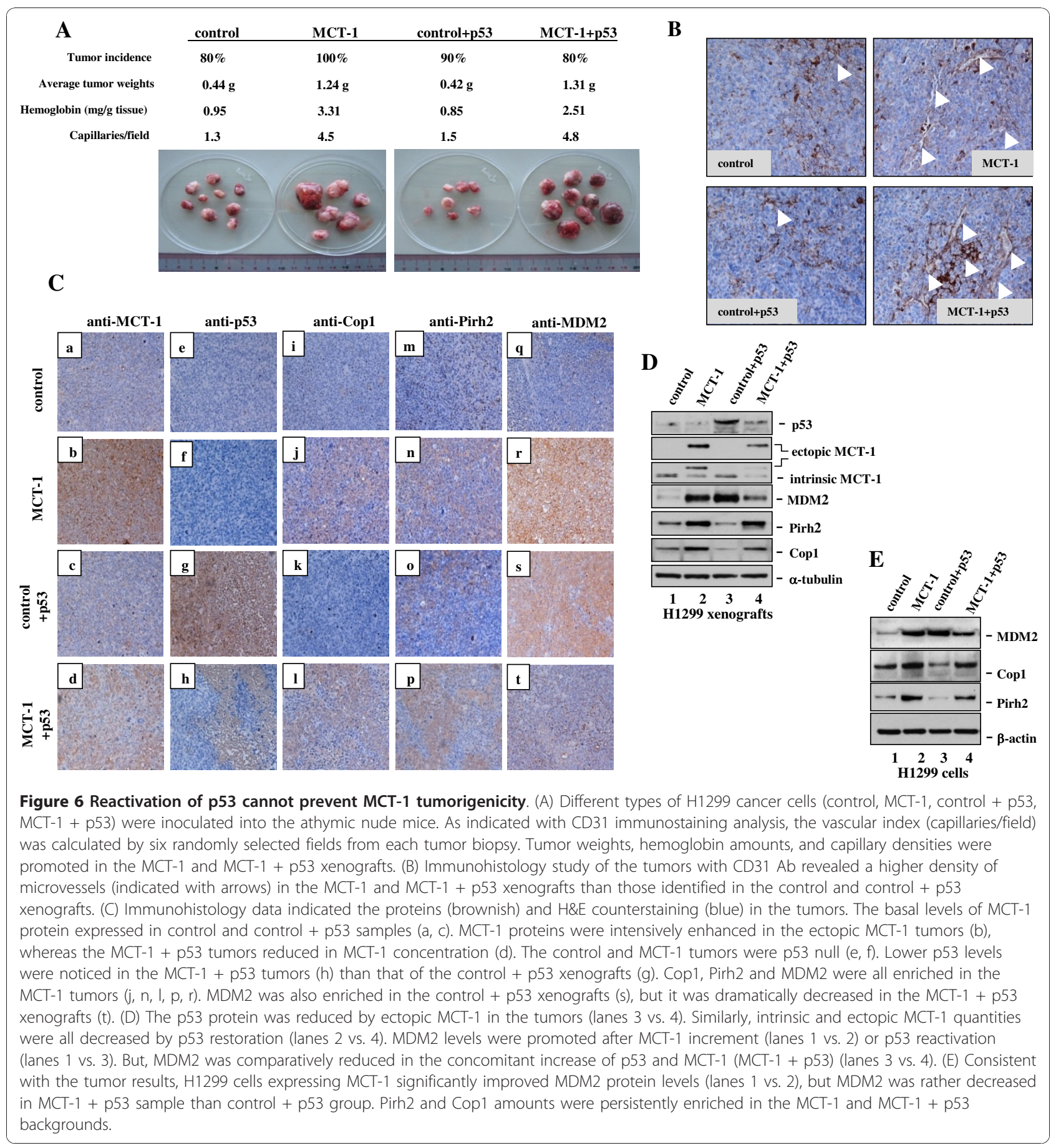

MCT-1 xenografts produced drastically larger tumors containing with higher hemoglobin levels $(\mathrm{p}<0.0001)$ and vascular counts $(\mathrm{p}<0.0001)$ than those were identified in the control and control $+\mathrm{p} 53$ xenografts. Though $\mathrm{p} 53$ functionally activated p21 expression (Figure 4F), the wild-type $p 53$ gene transfer still unsuccessfully repressed tumor growth in ectopic MCT-1 background that concomitantly increased in micro-vascularization as evaluated with the endothelial marker CD31 immunohistology staining (Figure 6B). As a result, the tumorigenicity and angiogenecity are not suppressed by p53 renovation; probably due to p53 only function effectively in the early tumor initiation stage. Once the tumors have developed, p53 activation disables to repair the genetic mutations and control the tumor growth.

The interrelation between p53 and MCT- 1 in the tumors were subsequently verified by immunohistochemistry study 
(Figure 6C, a-t). Consistent with in vitro cellular results, MCT-1 was also decreased markedly in the tumors with p53 expression (MCT-1 + p53) (d). However, MCT-1 was produced highly in the tumors without p53 (MCT-1) (b). Though p53 was greatly restored in the H1299 background (control $+\mathrm{p} 53)(\mathrm{g})$, it was still comparatively reduced because ectopic MCT-1 induction (MCT-1 + p53) (h). Intriguingly, the p53 suppressors, Cop1 and Pirh2, were stimulated predominantly in ectopic MCT-1 background ( $j$, $\mathrm{n}, \mathrm{l}, \mathrm{p})$. Although MDM2 amounts were significantly enhanced either by ectopic MCT-1 (MCT-1) (r) or by p53 restoration (control $+\mathrm{p} 53)(\mathrm{s})$, the p53-mediated MDM2 induction in tumors was declined strikingly while simultaneously expressing MCT-1 and p53 (MCT-1 + p53) (t).

These protein expressions were furthermore inspected in the tumors (Figure 6D). Due to p53 influence, lower intrinsic and ectopic MCT-1 levels were detected in MCT-1 + p53 tumors than in MCT-1 tumors (lanes 2 vs. 4). On the other hand, less p53 quantities observed in the MCT $-1+$ p53 tumors than in control + p53 ones (lanes 3 vs. 4). These indicate that MCT-1 works against p53 in the tumor development. Consistent with the findings in MCF-10A (Figure 1E), the auto-regulation of MCT-1 was manifestly detected in vivo because endogenic MCT-1 decreased in quantity as ectopic MCT-1 expressed (lanes 1 vs. 2).

MDM2 oncogene is trans-activated by $\mathrm{p} 53$, functioning as an E3 ubiquitin ligase to promote p53 degradation [40]. Our results had shown that MDM2 quantities were remarkably elevated in the MCT-1 xenografts as compared with the control H1299 xenografts (lanes 1 vs. 2). Even though MDM2 was promoted in the p53 renovation (control + p53) (lanes 1 vs. 3) (Figure 6D), the extent of MDM2 induced by p53 became insignificant when exogenic MCT-1 suppressed p53 action on MDM2 stimulation (lanes 3 vs. 4). As well, ectopic MCT-1 intensified Pirh 2 and Cop1 productions that potentially destabilized p53 protein (lanes 1 vs. 2). Likewise, the appearances of MDM2, Pirh2, and Cop1 in the H1299 cellular context were equivalent with their manifestations in tumors (Figure 6E). Stimulations of MDM2, Pirh2, and Cop1 could explain how oncogenic MCT-1 attenuates p53 protein accumulation and tumor-suppressive role during tumor development as the literatures report [41-43].

Supportive evidence was acquired from qRT-PCR analysis as well. MCT-1 mRNA levels in H1299 xenograft tumors were considerably decreased by $\mathrm{p} 53$ reactivation (Figure 7A) (MCT-1 vs. MCT-1 + p53, p < 0.0001). On the other hand, when the $p 53$ gene was transferred into H1299 cells, p53 transcripts were dramatically suppressed by ectopic MCT-1 (Figure 7B) (control + p53 vs. MCT-1 + p53, p < 0.0001). Unlike p53 gene deactivation, MDM2 mRNA levels were somewhat induced by ectopic MCT-1 (Figure 7C) (control vs. MCT-1, p <
0.0001). Though MDM2 transcripts were promoted in a p53-dependent mode, this consequence apparently decreased when MCT-1 inhibited p53 function (control + p53 vs. MCT $-1+$ p53, p < 0.0001). Differently, the transcripts of Pirh 2 and Cop1 genes constitutively promoted by ectopic MCT-1 were only moderately affected by p53 status (Figure 7D and 7E). Upregulation of MDM2, Pirh2, and Cop1 gene molecules provide other lines of evidence that MCT-1 downregulates p53 in tumorigenic process at the transcriptional stage.

In support of the tumorigenic outcomes, the phosphor-activation of AKT and MAPK were found to be enhanced in MCT-1 + p53 xenograft tumors relative to the other cohorts (control, control + p53, MCT-1) (Additional File 3A). Additionally, the integrin- $\beta 4$ was enriched particularly in MCT-1 + p53 xenograft tumors. Furthermore, the molecules involving in the oncogenic potential, H-Ras and HIF-1 $\alpha$ mRNA levels, all showed approximately 1.6 -fold increases in MCT-1 + p53 xenografts compared with those in the control + p53 xenografts (Additional File 3B). Stimulations of these anti-apoptotic molecules, which can enhance cancer cell proliferation and survival mechanisms, emphasize that the p53 reactivation under MCT-1 oncogenic stress fails to slow down the tumor development.

\section{Discussion}

\section{The antagonism between MCT-1 oncogene and p53 tumor suppressor}

MCT-1 oncogene is a dangerous foe to p53 function, playing multiple roles in promoting chromosome instability and tumor growth [36]. Constitutively activating $\mathrm{MCT}-1$ decreases $\mathrm{p} 53$ protein via a proteasome pathway [35]. We now demonstrate that MCT-1 reduces p53 mRNA levels accompanied with p53 gene promoter inactivation and p53 mRNA destabilization, which well correspond to inhibit p53-p21 pathway (Figure 4B-4F). Conversely, $M C T-1$ gene interference stimulates $p 53$ gene promoter and improves p53-p21 expression (Figure $4 \mathrm{C}$ and $4 \mathrm{G}$ ). Moreover, the original results have also demonstrated that $\mathrm{p} 53$ reciprocally interacts with the MCT-1 gene promoter that potentially suppresses MCT-1 oncogenicity in a feedback mechanism (Figure 2B-2D and Figure 3).

The mutual counteractions between p53 and MCT-1 at the gene and protein stages are comparable to the negative regulation between MDM2 and p53 [44,45]. As well, the reciprocated transcriptional repression between $\mathrm{MCT}-1$ and p53 resembles the mechanism of Twist oncogenic activity that obstructs the p53 tumor-suppressive function [46]. Another intriguing finding is that the induction of MCT-1 exerts a self-directed inhibition on intrinsic MCT1 protein (Figure 1D-1E, and 6D), by which the overall MCT-1 protein levels can be systematically controlled 


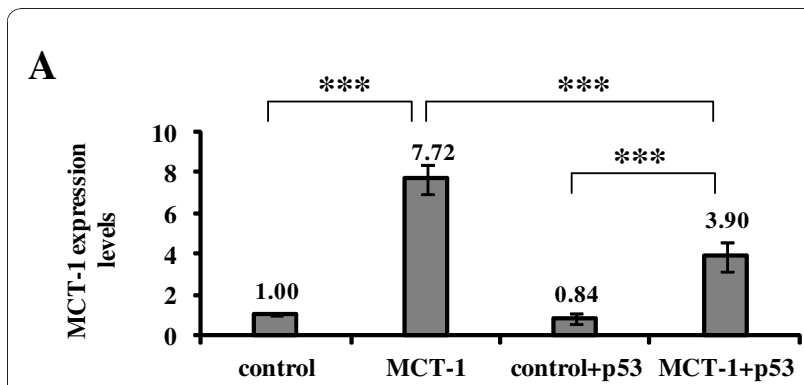

B

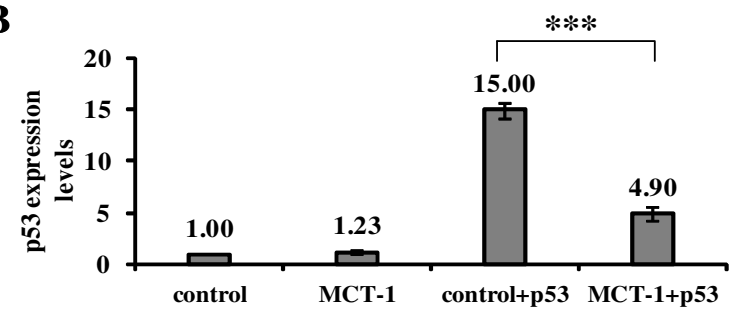

C

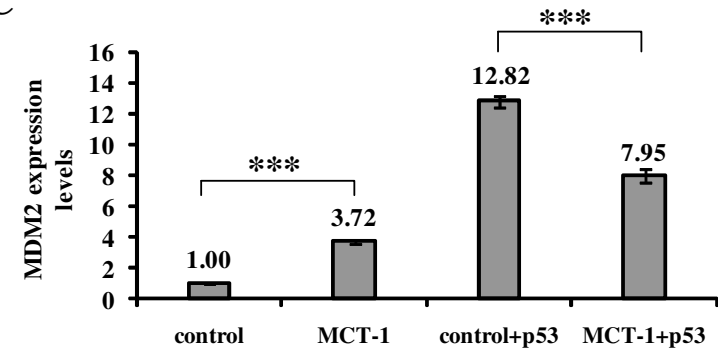

D

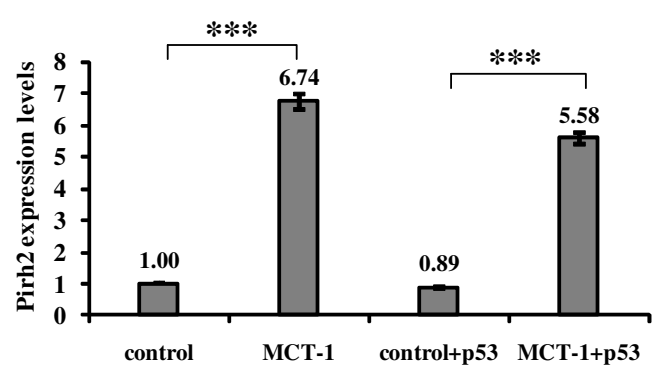

E

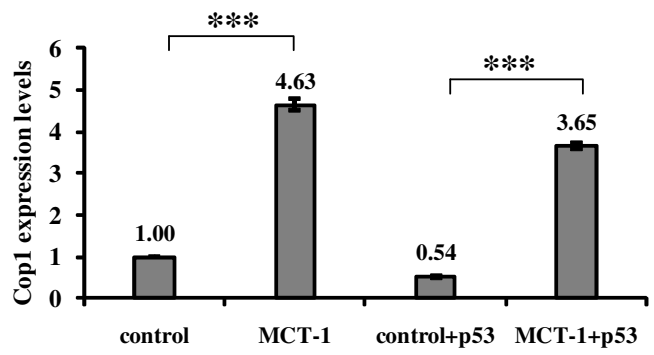

Figure 7 MCT-1 deactivates p53 but activates p53 inhibitors in tumor development. H1299 tumor biopsies were subjected to qRT-PCR analysis. (A) MCT-1 mRNA levels in the MCT-1 + p53 xenograft tumors were decreased comparative to the MCT-1 xenografts. (B) The p53 mRNA levels in the tumors were significantly declined in the MCT-1 + p53 xenografts relative to the control + p53 xenografts. (C) MDM2 mRNA amounts were moderately increased by ectopic MCT-1 and further promoted by p53 restoration. Low MDM2 mRNA levels were presented that was probably due to ectopic MCT-1 depress the p53 function. (D-E) Pirh2 and Cop1 mRNA levels were constitutively enhanced by oncogenic MCT-1 in a p53-independent manner. Statistical analysis was performed with the Student's t test. ${ }^{* *} p<0.0001$.

using an autonomous regulation in its promoter function (Figure 1E). The integral self-control could determine the steady state of MCT-1 activity that may critically regulate cell growth or tissue homeostasis. Similar effect has been identified that Myc overexpression contributes to tumorigenesis and myc expression is controlled through an autoregulatory circuit in non-transformed cells, by which elevated Myc protein amounts lead to down-regulation of myc transcription [47]. As well, overexpression of c-myc gene leads to a significant decrease in endogenous $\mathrm{N}$-myc levels [48].

\section{Reactivation of p53 cannot suppress MCT-1 tumor- promoting effect}

The tumor promotion in MCT-1 expressed H1299 xenografts represents the synergistic consequences of p53 null and MCT-1 induction (Figure 6). Our data have demonstrated that $\mathrm{p} 53$ reactivation cannot compromise the tumorigenic results induced by MCT-1 oncogene. MCT-1 + p53 xenograft mice thus develop significantly larger tumors with higher hemoglobin levels and micro-vessel density than the other xenograft tumors (control, MCT-1, control + p53). We have previously shown that $p 53$ gene add-in cannot rescue the p53-deficient cells from MCT-1 oncogenic impact on genome destabilization, but actually increases incidence of aneuploidy from $42.8 \%$ to $95 \%$ [36]. Thus, p53 renovation fails to inhibit MCT-1-induced aneuploidization that could predispose to many carcinogenic endpoints as the documents report [49]. Another important fact is that MCT-1 oncogene confers cellular resistance to the oxidative pressure depending on p53 function (Figure 5A). In the other way, the genotoxn-induced cytotoxicity is reduced particularly when p53 is abrogated in ectopic MCT-1 cells (Figure 5B). But independent of MCT-1 function, cell migratory ability is promoted predominantly by 553 deficiency (Figure $5 \mathrm{C}$ ), which could be coupled with the signaling activation of Rho pathway [39]. 
Regardless of p53 function, the tumor-promoting consequence is still largely promoted in A549 (p53 wild-type) lung cancer cells with a constitutive activation of MCT-1 (Figure 5D), further revealing that MCT-1 oncogenicity could overcome p53 action in the tumor development.

\section{The p53 inhibitors are stimulated in MCT-1 oncogenic background}

MCT-1 synergistically induces the oncogenic molecules in the p53 deficient background, which could be important for cell malignant transformation (Additional file 3 ). The biochemical and genetic information all support that ectopic MCT-1 induces tumor promotion accompanied with the enrichment of MDM2, Pirh2 and Cop1 in the tumors (Figure 6C-6D and 7C-7E), moreover explaining why p53 knock-in cannot suppress MCT-1 tumorigenic effects. In a p53-dependent manner, escalating p21 and MDM2 levels have been demonstrated that $\mathrm{p} 53$ restoration indeed actively regulates its downstream targets (Figure 4F and 6D-6E). Likewise, the reactive 553 capably depresses $\mathrm{MCT}-1$ protein in the MCT-1 + p53 xenograft tumors (Figure 6C-6D). Though MDM2 stimulated by 553 reconstitution, the MCT-1 inhibitory impact on p53 expression is also reflective to decline $M D M 2$ gene and protein in MCT-1 + p53 xenografts (Figure 6C-6D, 7C). Furthermore, MCT-1 dramatically enhances Pirh2 and Cop1 gene expressions that could eventually contribute to p53 destabilization (Figure 7D-7E). Overall, MCT-1 oncogenicity competently surpasses p53 tumor-suppressive ability that abolition of MCT-1 tumorigenic strength through gain of p53 function becomes impossible.

Ectopic MCT-1 enhances p53 negative regulators that can decline $\mathrm{p} 53$ function in tumor prevention in vivo. These negative influences as well reflect to upregulate MCT-1 promoter, MCT-1 mRNA stability, and overall MCT-1 mRNA amounts in vitro. MCT-1 promoter function reduced by wild-type p53 shows somewhat improvement in cells expressing MCT-1 (0.71) relative to control group (0.6) (Figure 1A), potentially because ectopic MCT-1 reduces the p53 depressing effect. In evaluation of MCT-1 mRNA turnover (Figure 1B), the p53-dependent suppression on MCT-1 mRNA stabilization is reduced by ectopic MCT-1 that MCT-1 mRNA is more stable in MCT-1 + p53 sample $\left(t_{1 / 2}=3.5\right)$ than control + p53 group $\left(t_{1 / 2}=3.1\right)$ $(\mathrm{p}<0.001)$. Besides, the overall MCT-1 mRNA levels in ectopic MCT-1 sample are much more enhanced (6.78) than control group (0.71) (Figure 1C). This is partly due to ectopic MCT-1 stimulate p53 inhibitors that can cancel the p53-dependent suppression on MCT-1 transcription.

Genetic evidence has implicated that $\alpha 6 \beta 4$ integrin signaling in promoting tumor angiogenesis and invasion [50]. These can be enhanced by HIF-1 $\alpha$ and Ras upexpression as well [51-54]. A selective enhancement of pro-survival molecules (Integrin- $\beta 4$, p-AKT, p-MAPK, H-RAS and HIF-1 $\alpha$ ) under MCT-1 oncogenic stress could increase cancer cell growth and angiogenecity that are substantially advantageous for tumor development (Additional file 3). The MDM2-p53 pathway has been recognized as an ideal therapeutic target for cancer treatment [55]. MCT-1 promotes angiogenesis that might be achieved by deregulating $\mathrm{p} 53$ downstream targets, such as, TSP1, VEGF, and COX-2 [56-58]; by inhibiting the MDM2-HIF- $1 \alpha$ interaction $[59,60]$; or by enhancing the Twist-HIF-1 $\alpha$ regulation [53]. Understanding of the crosstalk between MCT-1 and p53 in depth may facilitate the development of a new promising cancer therapeutic strategy that improves the therapeutic efficacy.

How do MCT-1 and p53 counteract each other? MCT-1 modulates p53 degradation through the extracellular signal-regulated kinase activity (ERK) because the ERK antagonist effectively restores p53-p21 expression [35]. In a negative feedback loop, p53 may deactivate ERK function to change MCT-1 stability [27]. Our important novel findings indicate that the S118A mutant of MCT-1 fails to inhibit p53 promoter activity but that is still affected by the mimetic ERK-phosphorylated MCT-1 (S118E and S118D) (Figure 4H). For that reason, MCT-1 could regulate the $p 53$ gene promoter involving ERK pathway, or direct interaction with ERK molecule [27,35]. In addition, p53 regulates and represses RNA poly III transcription activity that may control MCT-1 protein synthesis or the oncogenic effects on cell growth as the literatures indicate [61,62]. MCT-1 may also functionally resemble E6 and MDM2 oncoproteins, releasing RNA poly III from repression by p53 that highly enhances pol III transcription activity for protein synthesis, cell growth, and malignant phenotypes $[63,64]$.

\section{Conclusions}

Our results uncover an important reciprocated regulation between MCT-1 oncogene and p53 tumor suppressor. Achieving a counterbalance between them may determine tumor prevention or development. The wildtype $p 53$ gene reactivation is not capable to suppress the tumor growth promoted by MCT-1. Thus, $M C T-1$ gene knockout or dysfunction of MCT-1 activity could be another significant stratagem for inhibition of the tumorigenicity.

\section{Methods}

\section{Antibodies and reagents}

Antibodies (Abs) against the following proteins were purchased from different sources as indicated: p53, p21, Cop1, Pirh2, integrin- $\beta 4$ and AKT (Santa Cruz Biotechnology, Santa Cruz, CA); MDM2, $\alpha$-tubulin, GAPDH and 
$\beta$-actin (Abcam, Cambridge, UK); phospho-MAPK $\left(\mathrm{Thr}^{202} / \mathrm{Tyr}^{204}\right)$, phospho-AKT $\left(\mathrm{Ser}^{473}\right)$, phospho-p53 $\left(\mathrm{Ser}^{15}\right.$ ) and MAPK (Cell Signaling Technology, Danvers, MA); and CD31 (BD Pharmingen, San Diego, CA). The V5-epitope Ab (Invitrogen, Carlsbad, CA) identified the ectopically expressed V5-tagged MCT-1. The MCT-1 rabbit antibody (Zymed Laboratories Inc, San Francisco, CA) for detecting intrinsic MCT-1 was generated against a synthetic peptide (a.a. 72-88). Actinomycin-D and etoposide were acquired from Sigma (St. Louis, MO). pCMV-p53 and pCMV-p53mt135 plasmid DNA were obtained from Clontech Laboratories Inc. (Mountain View, CA).

\section{Cell culture and transfections}

Non-small cell lung cancer cells, H1299 (p53 null) were co-transfected with pLXSN/MCT-1-V5 and pCDNA3.1/ p53. Another lung cancer cell line A549 (p53 will-type) was transfected with pLXSN vector alone or pLXSN/ MCT-1-V5. The stable master cultures were established and maintained as previously described [35]. Normal breast epithelial MCF-10A cells were transfected with pLXSN or pLXSN/MCT-1-V5 that subsequently transfected with pMKO.1 puro p53 short hairpin RNA2 (shRNA2) or a mock vector as previously described [36]. The MCT-1 gene was abrogated in parental H1299 or MCF-10A cells by transfection with the pGeneClip MCTS1 shRNA vector (SA Biosciences Corp, Frederick, $\mathrm{MD}$ ), using jetPEI ${ }^{\mathrm{N}}$ transfection reagent (Polyplus-transfection, New York, NY). These stable transfectants were cultured with the medium containing puromycin $(0.5 \mu \mathrm{g} / \mathrm{ml})$.

\section{Quantitative real-time polymerase chain reaction (qRT- PCR)}

Total RNA was extracted from cells or mouse tumor tissues using TRIzol reagent (Invitrogen). The cDNA was synthesized from $2 \mu \mathrm{g}$ RNA using Oligo $(\mathrm{dT})_{12-18}$ primer and Superscript II reverse transcriptase (Invitrogen). MCT-1 mRNA levels were measured as previously described [36]. The specific primers for $p 53, M D M 2$, Cop1, Pirh2, HIF-1 $\alpha$ and H-Ras genes were designed by Primer Express software to ensure a single 72, 99, 123, 137, 76 and 69-bp amplicon. These probes were labeled NFQ (quencher) and FAM (reporter) and synthesized by Integrated DNA Technologies (Applied Biosystems, Foster City, CA). Reactions were performed in a $20 \mu \mathrm{l}$ reaction mixture containing 150 ng cDNA, $10 \mu \mathrm{l}$ TaqMan PCR Master Mix (Applied Biosystems) and $1 \mu \mathrm{l}$ corresponding TaqMan probe. Reactions were run on the ABI Prism 7900 Fast Real-Time PCR system in triplicate as follows: $95^{\circ} \mathrm{C}$ for $10 \mathrm{~min}, 45$ cycles of a 15 -second denaturing at $95^{\circ} \mathrm{C}$ and $1 \mathrm{~min}$ annealing at $60^{\circ} \mathrm{C}$. The mRNA levels were calculated. Cycle threshold $(\Delta \mathrm{Ct})=$ $\mathrm{Ct}$ target gene - $\mathrm{Ct}$ endogenous control (18S rRNA gene).

\section{Plasmid construction}

MCT-1 promoter DNA was isolated from the MCF-10A genome by PCR amplification using the forward primer, 5'-GAGCGGTACCAGGTTTTTAAATTTTT-3' (-1301 to -1284), and the reverse primer, 5'-GGAAGCTTTTAGGCAACCGG-3' $(+37$ to +25$)$. The PCR products were cloned into $\mathrm{Kpn} I$ and Hind $I I I$ restriction sites of pGL3-Luciferase basic vector (pGL3-MCT-1 promoter). The p53 promoter segment $(-188$ to +23$)$ was amplified by PCR using the forward primer, 5'-CGAGCTCGT CGGCGAGAATCCTGACT-3' (-188 to -170), and the reverse primer, 5'-GGAAGCTTGGACGGTGGCTCTA GACTTT-3' (+3 to +23). The PCR products were constructed in the pGL3-Luciferase basic vector with SacI and Hind III restriction sites (pGL3-p53 promoter). The 5'LTR promoter of the pLXSN vector was PCR-amplified with the primers 5'-GGGGTACCTAGACCACTCTACCCTATTC-3' and 5'-CCAAGCTTACACCC TAACTGACACACAT-3' to respectively generate KpnI and HindIII sites at the 5'-and 3'-ends of the DNA fragment. The amplified 5'LTR promoter was cloned into the pGL3-Luciferase basic vector using KpnI and HindIII sites (pGL3-5'LTR).

The CMV promoter was removed from pCDNA3.1 (+)/hygro vector using Mlu $I$ and Nhe $I$ and inserted into the pGL3-Luciferase basic vector with the same restriction sites to generate the CMV reporter construct (pGL3-CMV).

\section{Site-directed mutagenesis on MCT-1}

Three PCR primer sets were designed to generate the mutant strands of MCT-1 on Serine 118 residue (S118). The primer set for S118A included the forward primer 5'-GTCCAGGCTTAACTGCTCCTGGAGCTAAG-3' and the reverse primer 5'-CTTAGCTCCAGGAGCAGTTAAGCCTGGAC-3'. The primer set for S118D included the forward primer 5'-CATGTGTCCAGGCTTAACTGACCCTGGAGCTAAGCTTTAC-3' and the reverse primer 5'-GTAAAGCTTAGCTCCAGGGTCAGTTAAGCCTGGACACATG-3'. The primer set for S118E included the forward primer 5'-CATGTGTCCAGGCTTAACTGAGCCTGGAGCTAAGCTTTAC-3' and the reverse primer 5'-GTAAAGCTTAGCTCCAGGCTCAGTTAAGCCTGGACACATG-3'. Following the manufacturer's protocol for the GeneEditor ${ }^{\mathrm{mi}}$ in vitro site-directed mutagenesis system (Promega, Madison, WI), the insertion of wild-type MCT-1 constructed on pGEX-5X-1 plasmid was used as the mutagenesis template. The plasmid DNA was denatured, phosphorylated, annealed with the mutagenic oligonucleotides, and incubated with T4 DNA polymerase and T4 DNA ligase (Promega) at $37^{\circ} \mathrm{C}$ for $90 \mathrm{~min}$. Mutant plasmids were transformed into BMH 71-18 mutS competent cells and selected with the GeneEditor ${ }^{\mathrm{met}}$ antibiotic selection mix, 
and subsequently transformed into high-efficiency JM109 competent cells followed by the selection of the ampicillin and GeneEditor ${ }^{\text {Tx }}$ antibiotic selection mix. For long term storage, the mutants were transformed into the DH5 $\alpha$ competent cells.

Wild-type MCT-1 cDNA was digested from pLXSNMCT-1 plasmid by EcoRI \& XhoI. Point mutant inserts were digested from pGEX-5X-1-MCT-1 mutant plasmid by EcoRI and BamHI. Inserts were amplified by pfu DNA polymerase (Stratagene, La Jolla, CA) using FMCT1-Hpa (forward primer 5'-CCCGTTAACGCCACCATGTTCAAGAAATTTGATGAAAAAGAAAATG TG-3') and R-MCT1-Cla (reverse primer 5'-CCCATC GATTTTATTTCAGTTATCTAATTTGCGGCCGCTT TATATGTCTTCATATG CCACAGCCCATC-3'). PCR products were digested with $\mathrm{HpaI}$ and $\mathrm{Cla} I$ before constructing into pLHCX vector (BD Biosciences, Palo Alto, $\mathrm{CA})$. The recombinant plasmids were transformed into OneShot MachI T1 cells (Invitrogen), followed by colony PCR, enzyme digestion, and sequencing analysis. Three copies of FLAG Tag was PCR-priming from pCMV3Tag8 vector (Stratagene) with the FLAG Tag primer set, i.e. forward primer 5'-ATTTGCGGCCG CACTCGAGGATTACAAGGAT-3' and reverse primer 5'-TAAAGCGGCCGCCTATTTATCGTCATC-3'. The PCR product of three copies of Flag Tag was cloned into the Not $I$ site of pLHCX-MCT-1 plasmid. MOCK control (pLHCX vector alone) and FLAG-tagged pLHCX-MCT-1 (wild-type and mutants) plasmids were individually transfected into PT67 packaging cell line (BD Biosciences) using a Lipofectamine agent (Invitrogen). Transfectants were selected by $100 \mu \mathrm{g} / \mathrm{ml}$ hygromycin (MD Bio, Taipei, Taiwan). The viral supernatants were collected in a hygromycin-free medium and then infected MCF-10A cells (ATCC, Manassas, VA).

\section{Luciferase activity assay}

To analyze the luciferase activity, $0.5 \mu$ g reporter plasmid (pGL3-MCT-1 promoter, pGL3-p53 promoter, pGL3-5'LTR, or pGL3-CMV), $0.1 \mu \mathrm{g} \beta$-galactosidase plasmid, and $1 \mu$ l JetPEI reagent were mixed with $75 \mathrm{mM} \mathrm{NaCl}$ solution for $30 \mathrm{~min}$ before transfection into H1299 or MCF-10A cells. After $48 \mathrm{~h}$, the cells were washed with 1X PBS and incubated with $200 \mu$ lysis buffer (Promega) for $30 \mathrm{~min}$ at $-80^{\circ} \mathrm{C}$. Cell extracts $(70 \mu \mathrm{l})$ were added into 96-well microtiter plates and combined with $30 \mu \mathrm{l}$ luciferase assay reagent (Promega). The reaction was detected with a Hidex Chameleon machine, and then analyzed with Mikro Win2000 software. To analyze $\beta$-galactosidase activity, $30 \mu \mathrm{l}$ lysates were incubated with $22 \mu \mathrm{l} 1 \mathrm{X}$ ONPG, $47 \mathrm{mM}$ sodium phosphate, and $1 \mathrm{mM} \mathrm{MgCl}$ solution. Reactions were incubated at $37^{\circ} \mathrm{C}$ for $10 \mathrm{~min}$ and measured with the spectrophotometer at OD $420 \mathrm{~nm}$.

\section{Chromatin immunoprecipitation (ChIP) assay}

ChIP experiments were performed according to the manufacturer's protocol (Upstate Biotechnology, Lake Placid, NY). MCF-10A (p53 proficient) or p53-restored H1299 $\left(2 \times 10^{7}\right)$ cells were exposed to $40 \mu \mathrm{M}$ etoposide for $4 \mathrm{~h}$, fixed with $1 \%$ formaldehyde for $10 \mathrm{~min}$ at room temperature, neutralized with $125 \mathrm{mM}$ glycine for $5 \mathrm{~min}$, washed twice with PBS, and the cells were scraped off with PBS containing the protease inhibitor cocktail. Cell pellets were suspended in a $400 \mu \mathrm{l}$ SDS lysis buffer (1\% SDS, $10 \mathrm{mM}$ EDTA, $50 \mathrm{mM}$ Tris- $\mathrm{HCl}, \mathrm{pH}$ 8.0, protease inhibitor cocktail) and incubated on ice for 15 min followed by shearing of the genomic DNA into 200-1000 bp fragments by a sonicator (Bioruptor UCD-200). After cleaning the insoluble materials by centrifugation, supernatants were diluted with a $900 \mu \mathrm{l}$ ChIP dilution buffer (0.01\% SDS, 1\% Triton X-100, 1.2 mM EDTA, 167 $\mathrm{mM} \mathrm{NaCl}, 16.7 \mathrm{mM}$ Tris- $\mathrm{HCl}, \mathrm{pH}$ 8.1, protease inhibitor cocktail). Samples were pre-cleared with a $60 \mu \mathrm{l}$ salmon sperm DNA/Protein G agarose slurry for $1 \mathrm{~h}$ at $4^{\circ} \mathrm{C}$. An aliquot $(10 \mu \mathrm{l})$ of the supernatants were kept as input materials, and the remaining samples $(990 \mu \mathrm{l})$ were respectively incubated with $2 \mu \mathrm{g}$ p53 Ab, $2 \mu \mathrm{g}$ MCT-1 $\mathrm{Ab}, 1 \mu \mathrm{g}$ RNA polymerase II Ab (positive control), or $1 \mu \mathrm{g}$ normal mouse IgG (negative control) for $24 \mathrm{~h}$ at $4^{\circ}$ C. The protein-DNA immune complexes were incubated with $60 \mu \mathrm{l}$ salmon sperm DNA/Protein G agarose slurry for $1 \mathrm{~h}$ at $4^{\circ} \mathrm{C}$. Beads were washed sequentially with the low salt buffer (20 mM Tris- $\mathrm{HCl}$, pH 8.0, 2 mM EDTA, $150 \mathrm{mM} \mathrm{NaCl}, 0.1 \%$ SDS, $1 \%$ Triton X-100), the high salt buffer (20 mM Tris-HCl, pH 8.0, 2 mM EDTA, $500 \mathrm{mM}$ $\mathrm{NaCl}, 0.1 \%$ SDS, $1 \%$ Triton X-100), the LiCl buffer (250 $\mathrm{mM} \mathrm{LiCl}$, 1\% IGEPAL-CA630, $1 \mathrm{mM}$ EDTA, $10 \mathrm{mM}$ Tris-HCl, $\mathrm{pH} 8.0,1 \%$ deoxycholic acid), and then rinsed twice with TE buffer (10 mM Tris- $\mathrm{HCl}, \mathrm{pH} 8.0,1 \mathrm{mM}$ EDTA). Afterward, the protein-DNA complexes were eluted from the beads with $1 \%$ SDS $(200 \mu \mathrm{l})$ at room temperature for $15 \mathrm{~min}$. To reverse the cross-linked proteinDNA complexes, samples were diluted to $50 \mathrm{mM} \mathrm{NaCl}$ followed by incubation with $10 \mu \mathrm{g}$ RNaseA and $10 \mu \mathrm{g}$ proteinase $\mathrm{K}$ at $65^{\circ} \mathrm{C}$ for $24 \mathrm{~h}$. The eluted DNA was purified with a PCR Purification Kit (Qiagen, Valencia, CA) and subjected to the conventional PCR and q-PCR. Conventional PCR products were resolved on a $2 \%$ agarose gel and stained with ethidium bromide. For q-PCR analysis, we employed the SYBR green system using the ABI Prism 7900 Fast Real-Time PCR system and determined the threshold cycle numbers $(\mathrm{Ct})$. All the relative $\mathrm{Ct}$ values were normalized to the inputs and compared between samples.

\section{Electrophoretic-mobility shift assay (EMSA)}

EMSA was conducted with a Gel-Shift kit according to the manufacturer's protocol (Panomics, Fremont, CA). 
The nuclear extracts were prepared after MCF-10A $(2 \times$ $10^{7}$ ) cells were exposed to $40 \mu \mathrm{M}$ etoposide (ETO) for $4 \mathrm{~h}$. The biotin-labeled MCT-1 promoter probes (166, 173 and $199 \mathrm{bp}$ ) corresponding to the nucleotides -1301 to $-1135,-1142$ to -969 , and -1000 to -801 on the promoter regions were PCR amplified by forward and reverse primers as listed (Additional File 2). The PCR-amplified DNA probes were clarified by gel extraction kit (Qiagen). Nuclear extracts $(5 \mu \mathrm{g})$ were pre-incubated with $1 \mathrm{X}$ EMSA binding buffer and $1 \mu \mathrm{g}$ poly $\mathrm{d}(\mathrm{I}-\mathrm{C})$ for $5 \mathrm{~min}$ at room temperature followed by incubation with $30 \mathrm{ng}$ of biotin-labeled MCT-1 probe at $15^{\circ} \mathrm{C}$ for $30 \mathrm{~min}$. The competition experiments were performed by including a 100- or 200-fold excess of unlabeled wild-type or mutant p53 consensus sequences in the reactions for $20 \mathrm{~min}$ prior to incubation with the biotin-labeled probe. For the super-shift assay, $1 \mu \mathrm{g}$ of p53 antibody (SC-126 X) (Santa Cruz) was pre-incubated with the reaction for $1 \mathrm{~h}$ prior to adding the probe. Protein-DNA complexes were resolved with $6 \%$ non-denaturing polyacrylamide gel in $0.5 \mathrm{X}$ Tris-borate/EDTA buffer $(100 \mathrm{mM}$ Tris, $90 \mathrm{mM}$ boric acid, $1 \mathrm{mM}$ EDTA) at $4{ }^{\circ} \mathrm{C}$ and transferred to an Immobilon positively-charged nylon membrane (Millipore, Billerica, MA) for $1 \mathrm{~h}$ at $300 \mathrm{~mA}$. The transferred oligonucleotides were immobilized by UV crosslinking for $3 \mathrm{~min}$. The membranes were reacted with the blocking buffer followed by reaction with Streptavidin-HRP and development with ECL reagent.

\section{Cell apoptotic analysis}

To evaluate apoptotic cell death, MCF-10A cells were treated with $5 \mu \mathrm{M} \mathrm{H}_{2} \mathrm{O}_{2}$ or $40 \mathrm{mU}$ Bleomycin for $24 \mathrm{~h}$ followed by staining with a Annexin $\mathrm{V}$ apoptosis detection kit (BD Biosciences) for $15 \mathrm{~min}$. Afterward, apoptotic cells were evaluated by BD FACS Calibur Flow Cytometry (Becton-Dickinson, San Jose, CA).

\section{Cell migration assay}

MCF-10A cells were essayed for migratory ability with $\mathrm{QCM}^{\mathrm{\tau}}$ 24-Well Fluorimetric Cell Migration Array Kit (Chemicon International Inc., Temecula, CA). Cells $(5 \times$ $10^{5}$ cells) were seeded in the culture chamber with an $8 \mu \mathrm{m}$ pore size polycarbonate membrane. Five hundred microliter of serum-free or the complete DMEM/F-12 medium was added to the lower chamber. After incubating for $16 \mathrm{~h}$ at $37^{\circ} \mathrm{C}$ in a $\mathrm{CO}_{2}$ incubator, the non-migratory cells were carefully removed and the chamber membranes were inserted into a fresh well with $225 \mu \mathrm{l}$ pre-warmed Cell Detachment Solution for $30 \mathrm{~min}$ in a $37^{\circ} \mathrm{C}$ incubator to detach cells, followed by adding $75 \mu$ Lysis Buffer/ CyQuant $\mathrm{GR}^{\oplus}$ dye solution for $15 \mathrm{~min}$ at room temperature. Reaction mixtures $(200 \mu \mathrm{l})$ were added into a 96-well micro-titer plate for detection of fluorescence absorbance at excitation/emission filter sets 485/530 nm using a Hidex Plate Chameleon (SisLab, Milano, Italy) apparatus.

\section{Tumorigenicity, hemoglobin assay, and immunohistochemistry studies}

Eight-week-old female BALB/c nude mice (BALB/cAnNFoxn1nu/CrlNarl) were injected with H1299 cancer cells (control, MCT-1, control + p53, MCT-1 + p53). This animal experiment was approved by Animal Use Protocol in National Health Research Institutes (NHRI-IACUC-096049A). Each mouse was inoculated with $2 \times 10^{6}$ cells suspended in $100 \mu \mathrm{l}$ RPMI medium at both subcutaneous sites. When tumor sizes had reached approximately 4-6 $\mathrm{mm}$, the tumors were resected and weighed. The portions of tumor tissues were processed for hemoglobin levels, immunoblotting, qRT-PCR, and immunohistochemistry analysis as previously described [36].

\section{Additional material}

\begin{abstract}
Additional file 1: Luciferase activity of the pGL3-5'LTR (pLXSN) promoter and the pGL3-CMV (pCDNA3.1) promoter in H1299 cells. (A) There were no significant changes of 5'LTR promoter ( $\mathrm{pLXSN}$ vector) activity in the presence or absence of p53. (B) Ectopic expression of MCT-1 did not affect CMV (pCDNA vector) promoter activity in either p53-null or p53-positive conditions.

Additional file 2: Sequences of the primers, the probes, and the competitors. Lists of primer sequences used for ChIP and EMSA assays, as well the nucleotide sequence of wild-type and the site-specific mutant of p53-responsive elements used for the EMSA competition assays.

Additional file 3: Oncogenic molecules are promoted in the MCT-1 xenograft tumors. (A) The significant elevations of integrin- $\beta 4, p-A K T$, and p-MAPK proteins were particularly recognizable in the MCT-1 + p53 tumors, whereas these proteins were rather reduced in other types of xenograft tumors (control, MCT-1, and control + p53). (B) The expressions of $H$-Ras and HIF- $\alpha$ genes, potentially relating to cell malignancy, were promoting in the MCT-1 + p53 xenograft tumors.
\end{abstract}

List of abbreviations

MCT-1: multiple copies in T-cell malignancy 1; bp: base pair; mRNA: messenger RNA; shRNA: short hairpin RNA; NFQ: non-fluorescent quencher; FAM: 5-carboxyfluorescein; PBS: phosphate-buffered saline; HRP: horseradish peroxidase; ChIP: chromatin immunoprecipitation; EMSA: electrophoretic mobility shift assay; qRT-PCR: quantitative real-time polymerase chain reaction; Luc: firefly luciferase; Ab: antibody; min: minute; H\&E: hematoxylin and eosin; ECL: enhanced chemiluminescence; ETO: etoposide.

\section{Acknowledgements}

This work was funded by National Health Research Institutes (98A1-MGPP06014), National Science Council (NSC 96-2628-B-400-003-MY3; NSC 98-3112-B400-008), and partially supported by DOH99-TD-C-111-004 grants. This research was also conducted under the Graduate Program of Biotechnology in Medicine sponsored by the National Tsing Hua University and the National Health Research Institutes.

\section{Author details}

${ }^{1}$ Division of Molecular and Genomic Medicine, National Health Research Institutes, 35 Keyan Road, Zhunan, Miaoli County 350, Taiwan. ${ }^{2}$ Institute of Molecular Medicine, National Tsing Hua University, Hsinchu 300, Taiwan. 


\section{Authors' contributions}

RK performed q-RT-PCR, CHIP, EMSA, cloning, luciferase, Western blotting, animal experiments, and sketched the manuscript. HJS performed gene silencing, DNA cloning, Western blotting, and cell migration analysis. MHW performed the cell cycle profiling study. COC performed apoptotic analysis. TDL helped with luciferase reporter assays in MCT-1 mutants. LC did immunohistochemistry study. HLH supported and supervised the entire project, interpreted data, and approved publication after critically revising the manuscript. All authors have read and approved the final paper.

\section{Competing interests}

The authors declare that they have no competing interests

Received: 22 August 2010 Accepted: 7 December 2010

Published: 7 December 2010

\section{References}

1. Sherr CJ: Principles of tumor suppression. Cell 2004, 116:235-246

2. Vogelstein B, Kinzler KW: Cancer genes and the pathways they control. Nat Med 2004, 10:789-799.

3. Soussi T, Lozano G: p53 mutation heterogeneity in cancer. Biochem Biophys Res Commun 2005, 331:834-842.

4. Vogelstein B, Lane D, Levine AJ: Surfing the p53 network. Nature 2000, 408:307-310.

5. Vousden KH, Lane DP: p53 in health and disease. Nat Rev Mol Cell Biol 2007, 8:275-283.

6. el-Deiry WS, Kern SE, Pietenpol JA, Kinzler KW, Vogelstein B: Definition of a consensus binding site for p53. Nat Genet 1992, 1:45-49.

7. Gottlieb TM, Oren M: p53 in growth control and neoplasia. Biochim Biophys Acta 1996, 1287:77-102.

8. Levine AJ: p53, the cellular gatekeeper for growth and division. Cell 1997, 88:323-331.

9. Leng RP, Lin Y, Ma W, Wu H, Lemmers B, Chung S, Parant JM, Lozano G, Hakem R, Benchimol S: Pirh2, a p53-induced ubiquitin-protein ligase, promotes p53 degradation. Cell 2003, 112:779-791.

10. Dornan D, Wertz I, Shimizu H, Arnott D, Frantz GD, Dowd P, O'Rourke K, Koeppen H, Dixit VM: The ubiquitin ligase COP1 is a critical negative regulator of p53. Nature 2004, 429:86-92.

11. el-Deiry WS, Tokino T, Velculescu VE, Levy DB, Parsons R, Trent JM, Lin D, Mercer WE, Kinzler KW, Vogelstein B: WAF1, a potential mediator of p53 tumor suppression. Cell 1993, 75:817-825.

12. Barak $Y$, Juven $T$, Haffner $R$, Oren $M: m d m 2$ expression is induced by wild type p53 activity. EMBO J 1993, 12:461-468.

13. Miyashita T, Reed JC: Tumor suppressor p53 is a direct transcriptional activator of the human bax gene. Cell 1995, 80:293-299.

14. Morris GF, Bischoff JR, Mathews MB: Transcriptional activation of the human proliferating-cell nuclear antigen promoter by p53. Proc Natl Acad Sci USA 1996, 93:895-899.

15. Li M, Brooks CL, Wu-Baer F, Chen D, Baer R, Gu W: Mono- versus polyubiquitination: differential control of $\mathrm{p} 53$ fate by Mdm2. Science 2003, 302:1972-1975.

16. Cawley S, Bekiranov S, Ng HH, Kapranov P, Sekinger EA, Kampa D, Piccolboni A, Sementchenko V, Cheng J, Williams AJ, et al: Unbiased mapping of transcription factor binding sites along human chromosomes 21 and 22 points to widespread regulation of noncoding RNAs. Cell 2004, 116:499-509.

17. Wei $C L$, Wu Q, Vega VB, Chiu KP, Ng P, Zhang T, Shahab A, Yong HC, Fu Y, Weng $Z$, et al: A global map of $\mathrm{p} 53$ transcription-factor binding sites in the human genome. Cell 2006, 124:207-219.

18. Kim E, Giese A, Deppert W: Wild-type p53 in cancer cells: when a guardian turns into a blackguard. Biochem Pharmacol 2009, 77:11-20.

19. Janicke RU, Sohn D, Schulze-Osthoff K: The dark side of a tumor suppressor: anti-apoptotic p53. Cell Death Differ 2008, 15:959-976.

20. Sharpless NE, DePinho RA: p53: good cop/bad cop. Cell 2002, 110:9-12.

21. Vousden KH: Outcomes of p53 activation-spoilt for choice. J Cell Sci 2006, 119:5015-5020.

22. Essmann F, Pohlmann S, Gillissen B, Daniel PT, Schulze-Osthoff K, Janicke RU: Irradiation-induced translocation of p53 to mitochondria in the absence of apoptosis. J Biol Chem 2005, 280:37169-37177.
23. Budanov AV, Sablina AA, Feinstein E, Koonin EV, Chumakov PM: Regeneration of peroxiredoxins by p53-regulated sestrins, homologs of bacterial AhpD. Science 2004, 304:596-600.

24. Sablina AA, Budanov AV, llyinskaya GV, Agapova LS, Kravchenko JE, Chumakov PM: The antioxidant function of the p53 tumor suppressor. Nat Med 2005, 11:1306-1313.

25. Bensaad K, Tsuruta A, Selak MA, Vidal MN, Nakano K, Bartrons R, Gottlieb E, Vousden KH: TIGAR, a p53-inducible regulator of glycolysis and apoptosis. Cell 2006, 126:107-120

26. Shi B, Hsu HL, Evens AM, Gordon LI, Gartenhaus RB: Expression of the candidate MCT-1 oncogene in B- and T-cell lymphoid malignancies. Blood 2003, 102:297-302.

27. Dai B, Zhao XF, Hagner P, Shapiro P, Mazan-Mamczarz K, Zhao S, Natkunam Y, Gartenhaus RB: Extracellular signal-regulated kinase positively regulates the oncogenic activity of MCT-1 in diffuse large Bcell lymphoma. Cancer Res 2009, 69:7835-7843.

28. Dierov J, Prosniak M, Gallia G, Gartenhaus RB: Increased G1 cyclin/cdk activity in cells overexpressing the candidate oncogene, MCT-1. J Cell Biochem 1999, 74:544-550.

29. Prosniak M, Dierov J, Okami K, Tilton B, Jameson B, Sawaya BE, Gartenhaus RB: A novel candidate oncogene, MCT-1, is involved in cell cycle progression. Cancer Res 1998, 58:4233-4237.

30. Hsu HL, Shi B, Gartenhaus RB: The MCT-1 oncogene product impairs cell cycle checkpoint control and transforms human mammary epithelial cells. Oncogene 2005, 24:4956-4964.

31. Levenson AS, Thurn KE, Simons LA, Veliceasa D, Jarrett J, Osipo C, Jordan VC, Volpert OV, Satcher RL, Gartenhaus RB: MCT-1 oncogene contributes to increased in vivo tumorigenicity of MCF7 cells by promotion of angiogenesis and inhibition of apoptosis. Cancer Res 2005, 65:10651-10656.

32. Fleischer TC, Weaver CM, McAfee KJ, Jennings JL, Link AJ: Systematic identification and functional screens of uncharacterized proteins associated with eukaryotic ribosomal complexes. Genes Dev 2006, 20:1294-1307.

33. Mazan-Mamczarz K, Hagner PR, Corl S, Srikantan S, Wood WH, Becker KG, Gorospe M, Keene JD, Levenson AS, Gartenhaus RB: Post-transcriptional gene regulation by HuR promotes a more tumorigenic phenotype. Oncogene 2008, 27:6151-6163.

34. Reinert LS, Shi B, Nandi S, Mazan-Mamczarz K, Vitolo M, Bachman KE, He H, Gartenhaus RB: MCT-1 protein interacts with the cap complex and modulates messenger RNA translational profiles. Cancer Res 2006, 66:8994-9001.

35. Hsu HL, Choy CO, Kasiappan R, Shih HJ, Sawyer JR, Shu CL, Chu KL, Chen YR, Hsu HF, Gartenhaus RB: MCT-1 oncogene downregulates p53 and destabilizes genome structure in the response to DNA doublestrand damage. DNA Repair (Amst) 2007, 6:1319-1332.

36. Kasiappan R, Shih HJ, Chu KL, Chen WT, Liu HP, Huang SF, Choy CO, Shu CL, Din R, Chu JS, Hsu HL: Loss of p53 and MCT-1 overexpression synergistically promote chromosome instability and tumorigenicity. Mol Cancer Res 2009, 7:536-548.

37. Wang S, El-Deiry WS: $p 73$ or $p 53$ directly regulates human $p 53$ transcription to maintain cell cycle checkpoints. Cancer Res 2006, 66:6982-6989.

38. Sun X, Shimizu H, Yamamoto K: Identification of a novel p53 promoter element involved in genotoxic stress-inducible p53 gene expression. Mol Cell Biol 1995, 15:4489-4496.

39. Roger L, Gadea G, Roux P: Control of cell migration: a tumour suppressor function for p53? Biol Cell 2006, 98:141-152, Review.

40. Haupt $Y$, Maya R, Kazaz A, Oren M: Mdm2 promotes the rapid degradation of p53. Nature 1997, 387:296-299.

41. Dornan D, Bheddah S, Newton K, Ince W, Frantz GD, Dowd P, Koeppen H, Dixit VM, French DM: COP1, the negative regulator of $\mathrm{p} 53$, is overexpressed in breast and ovarian adenocarcinomas. Cancer Res 2004 64:7226-7230.

42. Ganguli G, Wasylyk B: p53-independent functions of MDM2. Mol Cancer Res 2003, 1:1027-1035.

43. Wang $X M$, Yang $L Y$, Guo L, Fan C, Wu F: p53-induced RING-H2 protein, a novel marker for poor survival in hepatocellular carcinoma after hepatic resection. Cancer 2009, 115:4554-4563. 
44. Momand J, Zambetti GP, Olson DC, George D, Levine AJ: The mdm-2 oncogene product forms a complex with the p53 protein and inhibits p53-mediated transactivation. Cell 1992, 69:1237-1245.

45. Wu X, Bayle JH, Olson D, Levine AJ: The p53-mdm-2 autoregulatory feedback loop. Genes Dev 1993, 7:1126-1132.

46. Shiota M, Izumi H, Onitsuka T, Miyamoto N, Kashiwagi E, Kidani A, Hirano G, Takahashi M, Naito S, Kohno K: Twist and p53 reciprocally regulate target genes via direct interaction. Oncogene 2008, 27:5543-5553.

47. Kim MK, Carroll WL: Autoregulation of the $\mathrm{N}$-myc gene is operative in neuroblastoma and involves histone deacetylase 2. Cancer 2004, 101:2106-2115.

48. Sivak LE, Tai KF, Smith RS, Dillon PA, Brodeur GM, Carroll WL: Autoregulation of the human $\mathrm{N}$-myc oncogene is disrupted in amplified but not single-copy neuroblastoma cell lines. Oncogene 1997, 15:1937-1946.

49. Weaver BA, Cleveland DW: Does aneuploidy cause cancer? Curr Opin Cell Biol 2006, 18:658-667.

50. Nikolopoulos SN, Blaikie P, Yoshioka T, Guo W, Giancotti FG: Integrin beta4 signaling promotes tumor angiogenesis. Cancer Cell 2004, 6:471-483.

51. Giehl K: Oncogenic Ras in tumour progression and metastasis. Biol Chem 2005, 386:193-205

52. Yang MH, Wu KJ: TWIST activation by hypoxia inducible factor-1 (HIF-1): implications in metastasis and development. Cell Cycle 2008, 7:2090-2096.

53. Yang MH, Wu MZ, Chiou SH, Chen PM, Chang SY, Liu CJ, Teng SC, Wu KJ: Direct regulation of TWIST by HIF-1alpha promotes metastasis. Nat Cell Biol 2008, 10:295-305.

54. Zhong H, De Marzo AM, Laughner E, Lim M, Hilton DA, Zagzag D, Buechler P, Isaacs WB, Semenza GL, Simons JW: Overexpression of hypoxia-inducible factor 1alpha in common human cancers and their metastases. Cancer Res 1999, 59:5830-5835.

55. Shangary S, Wang S: Targeting the MDM2-p53 interaction for cancer therapy. Clin Cancer Res 2008, 14:5318-5324.

56. Duarte ML, de Moraes E, Pontes E, Schluckebier L, de Moraes JL, Hainaut $P$, Ferreira CG: Role of p53 in the induction of cyclooxygenase-2 by cisplatin or paclitaxel in non-small cell lung cancer cell lines. Cancer Lett 2009, 279:57-64.

57. el-Deiry WS: Regulation of $\mathrm{p} 53$ downstream genes. Semin Cancer Biol 1998, 8:345-357.

58. de Moraes E, Dar NA, de Moura Gallo CV, Hainaut P: Cross-talks between cyclooxygenase-2 and tumor suppressor protein p53: Balancing life and death during inflammatory stress and carcinogenesis. Int I Cancer 2007, 121:929-937.

59. Nieminen AL, Qanungo S, Schneider EA, Jiang BH, Agani FH: Mdm2 and HIF-1alpha interaction in tumor cells during hypoxia. J Cell Physiol 2005, 204:364-369.

60. Carroll VA, Ashcroft M: Regulation of angiogenic factors by HDM2 in renal cell carcinoma. Cancer Res 2008, 68:545-552.

61. Cairns CA, White RJ: p53 is a general repressor of RNA polymerase III transcription. EMBO J 1998, 17:3112-3123.

62. Felton-Edkins ZA, Kenneth NS, Brown TR, Daly NL, Gomez-Roman N, Grandori C, Eisenman RN, White RJ: Direct regulation of RNA polymerase III transcription by RB, p53 and c-Myc. Cell Cycle 2003, 2:181-184.

63. Stein T, Crighton D, Boyle JM, Varley JM, White RJ: RNA polymerase III transcription can be derepressed by oncogenes or mutations that compromise p53 function in tumours and Li-Fraumeni syndrome. Oncogene 2002, 21:2961-2970.

64. White RJ: RNA polymerase III transcription and cancer. Oncogene 2004, 23:3208-3216.

doi:10.1186/1476-4598-9-311

Cite this article as: Kasiappan et al: The antagonism between MCT-1

and p53 affects the tumorigenic outcomes. Molecular Cancer 2010 9:311.

\section{Submit your next manuscript to BioMed Central and take full advantage of:}

- Convenient online submission

- Thorough peer review

- No space constraints or color figure charges

- Immediate publication on acceptance

- Inclusion in PubMed, CAS, Scopus and Google Scholar

- Research which is freely available for redistribution

Submit your manuscript at www.biomedcentral.com/submit
Biomed Central 